\title{
IDENTIFICATION OF THE BYPRODUCTS OF THE OXYGEN EVOLUTION REACTION ON RUTILE-TYPE OXIDES UNDER DYNAMIC CONDITIONS
}

\author{
E. Kuznetsova ${ }^{\text {a }}$, A. Cuesta ${ }^{\text {b, c }}$, M. Thomassen ${ }^{\text {d, }}$ S. Sunde ${ }^{a, *}$ \\ ${ }^{a}$ Department of Material Science and Engineering, Norwegian University of Science and \\ Technology, Sem Sælands vei 12, NO-7491 Trondheim, Norway \\ b Instituto de Quimica Fisica “Rocasolano”, CSIC, C. Serrano 119, E-28006 Madrid, Spain \\ c Current address: Department of Chemistry, School of Natural and Computing Sciences, \\ University of Aberdeen, Aberdeen AB 243 UE, UK \\ d SINTEF Materials and Chemistry, NO-7465 Trondheim, Norway
}

\begin{abstract}
This paper examines the detection and quantification of the potentially corrosive byproducts of the oxygen evolution reaction on iridium and iridium-ruthenium mixed oxides. A conventional but stationary ring-disc electrode was employed in a flow cell configuration for the detection of volatile reaction product other than oxygen, and the formation of at least two active species was detected. Potential-modulated UV-VIS reflectance spectroscopy helped to identify one of these volatile reaction byproducts as hydrogen peroxide, and the other is tentatively suggested to be ozone. It was found that these species are formed under potentiodynamic conditions due to the chemical recombination of the absorbed reaction intermediates. The influence of the electrode material composition on the production yield of these byproducts was studied, and we found that the generation of these corrosive reaction byproducts is suppressed the more active the catalyst is for the OER. The formation of by-products can therefore be addressed by a rational choice of the electrode materials based on the adsorption energy of the reaction intermediates as is done for the OER itself. Steady-state electrolysis minimizes hydrogen peroxide formation as byproduct of the oxygen evolution reaction.
\end{abstract}

*Corresponding author. Tel +49 73594051

E-mail address: svein.sunde@material.ntnu.no (S. Sunde) 


\section{Introduction}

Pure hydrogen can be produced in an environment-friendly way with a low $\mathrm{CO}_{2}$ footprint by using electricity from renewable energy sources (solar, wind, hydropower) for electrochemical water splitting [1]. However, a key characteristic of renewable energy sources is their intermittent nature, which frequently results in a fluctuating voltage being supplied to the water electrolyzer. Therefore, it becomes essential that these electrolyzers are able to accept such fluctuations in the supplied power. If water electrolysis is to be integrated as an energy storage system in the renewable energy production chain, it is crucial to understand the mode of operation of the electrolyzers under dynamic conditions and not only in the steady state [2,3].

Currently three technologies for water electrolyzers exist, classified according to the kind of electrolyte employed: alkaline, proton exchange membrane (PEM) and solid oxide electrolysis. Although alkaline water electrolysis is widely used in industry, PEM electrolyzers are an alternative that does not require any corrosive electrolyte, and PEM electrolyzers offer high efficiency, compactness, low degradation rates and easy maintenance.

Rutile-type oxides, such as $\mathrm{RuO}_{2}$ and $\mathrm{IrO}_{2}$, are known as excellent catalysts for the oxygen evolution reaction (OER), the anodic reaction of water electrolysis [4], in PEM electrolysis. The activity of iridium dioxide is lower than that of ruthenium dioxide; however, the former is far more stable. Mixing of $\mathrm{IrO}_{2}$ and $\mathrm{RuO}_{2}$ has been shown to be particularly efficient for the stabilization of the catalysts without compromising the activity of $\mathrm{RuO}_{2}[5,6]$. This can be explained by the tendency of ruthenium to segregate towards the bulk when placed in an $\mathrm{IrO}_{2}$ matrix [7, 8]. Therefore, depending on the synthesis conditions, the surface of the mixed oxide is enriched in iridium. With adequate iridium concentrations, ruthenium oxide kink sites, which are the most unstable towards corrosion, will be protected by iridium, thereby significantly increasing the stability of the mixed iridium-ruthenium oxide electrodes.

The OER,

$$
2 \mathrm{H}_{2} \mathrm{O} \rightarrow \mathrm{O}_{2}+4 \mathrm{H}^{+}+4 e^{-} \quad \mathrm{E}^{0}=1.229 \mathrm{~V}
$$

as well as its reverse, the oxygen reduction reaction (ORR), is still not completely understood, and many reaction mechanisms have been proposed $[4,9,10,11,12]$. The formation of the oxygen molecule at the electrocatalyst surface can proceed through either a mononuclear $[13,14,15,16]$ or a binuclear $[17,18]$ pathway.

The mononuclear mechanism was used for a computational analysis of the trends in catalytic activity for oxygen evolution by Rossmeisl et al [14]. The mechanism assumes the formation of an $\mathrm{O}$ - $\mathrm{O}$ bond between a transition metal S-O* intermediate and a water molecule through the formation of 
the adsorbed hydroperoxy intermediate $\mathrm{S}-\mathrm{OOH}$ :

$\mathrm{H}_{2} \mathrm{O} \rightarrow \mathrm{HO}^{*}+\mathrm{H}^{+}+e^{-}$

$\mathrm{HO}^{*} \rightarrow \mathrm{O}^{*}+\mathrm{H}^{+}+e^{-}$

$\mathrm{O}^{*}+\mathrm{H}_{2} \mathrm{O} \rightarrow \mathrm{HOO}^{*}+\mathrm{H}^{+}+e^{-}$

$\mathrm{HOO}^{*} \rightarrow \mathrm{O}_{2}+\mathrm{H}^{+}+e^{-}$,

where * represents an active surface site, such as the coordinately unsaturated site on top of fivefoldcoordinated metal ions on the rutile (110) surface.

From the description of the mononuclear mechanism in Ref. [14] it follows that the electrocatalytic properties of the transition metal oxide can be improved by tuning the binding energy of $\mathrm{O}^{*}$, and a volcano plot describing the catalytic activity of metal oxides was derived. It was found that both $\mathrm{IrO}_{2}$ and $\mathrm{RuO}_{2}$ are good choices for the OER, but $\mathrm{IrO}_{2}$ bonds $\mathrm{O}^{*}$ more strongly and $\mathrm{RuO}_{2}$ more weakly than an ideal catalyst for OER should do.

In the binuclear mechanism [19, 20,21], the first step involves oxidation of water with the formation of $\mathrm{S}=\mathrm{O}$ species. The subsequent chemical steps correspond to an internal surface redox step whereby two neighboring $\mathrm{S}-\mathrm{O}^{*}$ groups produce a $\mu$-peroxo bridged intermediate $\mathrm{S}-\mathrm{O}-\mathrm{O}-\mathrm{S}$. This reaction is followed by the release of $\mathrm{O}_{2}$.

Both reaction mechanisms thus include $\mathrm{S}-\mathrm{O}^{*}$ reaction intermediates which can recombine with water with the formation of absorbed hydroperoxy species, $\mathrm{S}-\mathrm{OOH}$.

Hydroperoxy species have been detected as intermediates in the electrochemical evolution of oxygen on gold using surface-enhanced Raman spectroscopy (SERS) [22] and in the photocatalytic oxidation of water on $\mathrm{IrO}_{2}$ nanoclusters [23]. Hydroperoxy species can desorb from the transition metal active sites to the solution, which may result in a number of reactions. For example, the hydroperoxyl radical, HOO* is known to be unstable and to decompose readily to oxygen and hydrogen peroxide in protic media [24, 25].

The formation of hydrogen peroxide is also thermodynamically possible directly through electrochemical reactions at high anodic potentials:

$\mathrm{H}_{2} \mathrm{O}_{2}+2 \mathrm{H}^{+}+2 e^{-} \rightarrow 2 \mathrm{H}_{2} \mathrm{O} \quad \mathrm{E}^{\circ}=1.776 \mathrm{~V}$

or after direct recombination of oxygen and hydrogen due to hydrogen crossover through the membrane to the anode:

$\mathrm{H}_{2}+\mathrm{O}_{2} \rightarrow \mathrm{H}_{2} \mathrm{O}_{2}$

Ando and Tanaka [26] have proposed a new system in which the products of water electrolysis 
are hydrogen and hydrogen peroxide, produced simultaneously in order to benefit from the higher economic value of hydrogen peroxide as compared to oxygen. However, hydrogen peroxide is a very powerful oxidizing species in acidic solutions, and it can potentially provoke the dissolution of the transition metal oxides used as electrocatalysts. Moreover, the formation of hydrogen peroxide and radicals during water electrolysis promotes the chemical degradation of the Nafion membrane, a key component of the PEM electrolyzers, leading to a significant decrease of the electrolyzer's durability [27]. Thus, the formation of hydrogen peroxide during water electrolysis is important from the perspective of electrolyzer degradation, and it becomes important to delineate favorable operating conditions and to identify a catalyst that suppresses the formation of this species.

Formation of ozone and hydrogen peroxide during the OER has been reported at synthetic boron-doped diamond thin film anodes, which operate under significant anodic overpotentials in acidic media [28].

Commercial water electrolyzers typically operate at a voltage of $1.7-2 \mathrm{~V}$, and thus several of the reaction byproducts listed above may result on the anode, both under steady state and dynamic conditions, and ignorance or neglect of their impact may thus significantly decrease the electrolyzer lifetime.

The purpose of this paper is to quantify the formation of some potentially corrosive byproducts of the OER under dynamic high current conditions at the anodic catalysts for PEM water electrolysis. Since PEM technology employs composite electrodes in which the electrocatalyst is in intimate contact with the membrane material we perform our measurements for thin-layer electrodes to avoid issues of by-product diffusion and reaction within porous layers. Below we provide electrochemical and spectroscopic evidence that hydrogen peroxide and other volatile species are actually formed as a byproduct of the OER in acidic media. Finally, we address the consequences of the electrocatalyst composition on the hydrogen peroxide yields during the OER.

\section{Experimental}

\subsection{Electrode preparation}

Iridium oxide powders were used as electrode materials on the disk of the ring-disc electrode in the flow-cell measurements. The powders were prepared by the hydrolysis method as described in [29], except that the catalyst was not covered by any Nafion film which renders the working electrode free of any polymer. The precursors, $\mathrm{H}_{2} \mathrm{IrCl}_{6} \cdot 4 \mathrm{H}_{2} \mathrm{O}$ (OMG AG\&Co. KG, $99.2 \%$ ) and $\mathrm{RuCl}_{3} \cdot \mathrm{xH}_{2} \mathrm{O}$ (Sigma-Aldrich, ReagentPlus) (for the mixed iridium-ruthenium oxide) were dissolved in aqueous 0.2 $\mathrm{M} \mathrm{NaOH}$ solution (J. T. Baker, Baker Analyzed). The resulting solution was stirred at $80^{\circ} \mathrm{C}$ for one hour, before cooling and adjusting the $\mathrm{pH}$ to 8 with nitric acid (Merck, p.a.). After 30 additional minutes of stirring and heating at $80^{\circ} \mathrm{C}$, the precipitate was separated and washed by centrifuging at $5000 \mathrm{rpm}$. 
The precipitate was then heat-treated at $550{ }^{\circ} \mathrm{C}$ in air for 30 minutes. For the preparation of the thin film electrodes employed for the flow-cell experiment, the oxide catalysts prepared by the method described above were dissolved in water $\left(1 \mathrm{mg} \mathrm{mL}^{-1}\right)$ in an ultrasonic bath, and $20 \mu \mathrm{L}$ of the resulting dispersion was pipetted onto the central gold disc (6 mm in diameter) of a PINE E6 series ring-disc electrode assembly (platinum ring).

Anodic iridium oxide film (AIROF) electrodes formed anodically on an iridium disc were prepared as described in Reference [30], and were used for UV-potential-modulated reflectance spectroscopy (UV-PMRS) and for electrolysis of the solutions used for transmission UV-vis spectroscopy. Briefly, iridium metal electrodes were mechanically polished to a mirror finish with 5.0, 0.3 and $0.05 \mu \mathrm{m}$ alumina, rinsed with Milli-Q water and washed four successive times in an ultrasonic bath. They were then immersed in $0.5 \mathrm{M} \mathrm{H}_{2} \mathrm{SO}_{4}$ and cycled 200 times between 0 and $1.5 \mathrm{~V}$ at $100 \mathrm{mV}$ $\mathrm{s}^{-1}$ in order to grow the AIROF layers. An iridium metal sheet with an electrode area of $1.5 \mathrm{~cm}^{2}$ embedded in epoxy was used for the electrolysis experiments, and an iridium disc with a diameter of 1 $\mathrm{cm}$ cut from $1 \mathrm{~mm}$ thick iridium sheet and inserted in a polypropylene holder with a Viton O-ring was used for the UV-PMRS experiments.

\subsection{Flow-cell measurements}

Using the conventional rotating-ring disc cell arrangement for detection of the OER byproducts at the high potentials used in this work proved impossible due to the significant amount of gaseous products formed. These blocked the electrode surface and which could not be removed even at high rotation speeds. We therefore employed a modified flow-cell arrangement instead.

The experiments were performed in a four-electrode arrangement and were controlled by a PGSTAT128N MBA Aut mnolab bipotentiostat. An approximately $1 \mathrm{~cm}^{2}$ platinum foil and a reversible hydrogen electrode (RHE) were used as auxiliary and reference electrodes, respectively.

The flow-cell measurements were performed in a homemade electrochemical flow cell, a scheme of which is shown in Fig. 1. The cell is cylindrical, $6 \mathrm{~cm}$ in diameter, and consists of three parts: 1. a glass central part, opened at both ends and closed by two Teflon lids sealed by rubber O-rings; 2 . The bottom lid, in which the ring and the working disc electrodes are embedded; and 3. the top lid, which holds the reference and counter electrodes, an electrolyte inlet tube and an outlet tube.

The counter electrode consisted of a Pt foil separated from the rest of the cell by a glass tube interfaced to the compartment containing the working and reference electrodes through a glass frit.

During the experiments the electrolyte was continuously pumped through the electrochemical cell at a constant flow rate. Initially we attempted to use the conventional flow-cell arrangement reported in Ref. [31], in which the electrolyte is pumped at right angle towards the electrode. However, problems of gas-bubble removal also persisted to some degree even for this cell configuration. In order to 
maximize gas removal from the the electrode we employed instead a J-form glass tube for the pump outlet so that the electrolyte flow is made coplanar to the electrode surface. We found that this resulted in the reproducible detection of reaction products from the disk on the ring with a sufficient collection efficiency (see below). This arrangement thus allows for the capture of the OER by-products conveniently employing a conventional rotating ring-disc electrode.

The electrolyte flow rate was controlled by a pulsation-free Ismatec ISM 901 REGLO-Z Digital gear pump which has a flow rate stable over the time frame of the experiments performed. A flow rate of $300 \mathrm{~mL} \mathrm{~min}{ }^{-1}$ was found to be optimal for removing the gaseous products from the electrode surface, while still being small enough to avoid creating bubbles and turbulence in the pump piping. The flow cell arrangement turned out to provide fast reaction product transfer from the working to the ring electrode, which allowed close to real-time detection of the OER by-products.

The collection efficiency of the ring of the flow-cell electrodes was determined as with conventional rotating ring disc electrodes (RRDE), using $\mathrm{Fe}(\mathrm{CN})_{6}{ }^{4-} / \mathrm{Fe}(\mathrm{CN})_{6}{ }^{3-}$ redox couple. The collection efficiency of the electrodes in a conventional RRDE cell was determined to be $23.5 \%$ $\%$ according to the manufacturer's specification), while that obtained when employing the same electrode in the flow-cell configuration was of approximately $10 \%$. We ascribe the lower collection efficiency to the fact that under coplanar electrolyte flow, only the part of the ring electrode upstream of the flow can capture the species generated on the disc electrode. Collection efficiency estimated using the $\mathrm{Fe}(\mathrm{CN})_{6}{ }^{4-} / \mathrm{Fe}(\mathrm{CN})_{6}{ }^{3-}$ redox couple may be somewhat different from that of OER by-products from a porous electrode since at the reactions in the latter case will be expected to proceed also in the inner parts of the oxide. Consequently, any byproduct will have more chance to be re-adsorbed and react than in the case of a redox couple at a smooth electrode, and this will influence quantification of the byproducts at the ring. However, the discussion of the identity of the by-products and intermediates pursued here will not suffer significantly from any such inaccuracies in the numerical value of the collection efficiency is assumed to be of less importance. Similar considerations will apply to any experimental setup employing ring-disc electrodes, including RRDEs, and is not particular to the walljet cell employed here.

The cell was tested with respect to flow rate, distance between pump outlet and electrode, outlet tube diameter etc. We thus found an optimal operational combination of parameters which was then used for the entire range of experiments.

\section{$2.3 U V$-vis spectroscopy}

UV-vis absorption spectroscopy was used to evaluate hydrogen peroxide production during the OER by titrating small amounts of solution at different times with potassium permanganate. A UV3600 Schimadzu spectrometer was used. A $0.17 \mathrm{mM}$ solution of $\mathrm{KMnO}_{4}$ in $0.5 \mathrm{M} \mathrm{H}_{2} \mathrm{SO}_{4}$ was used as the titration solution and $0.5 \mathrm{M} \mathrm{H}_{2} \mathrm{SO}_{4}$ was utilized as a reference solution for the UV-vis experiments. 
All the solutions were purged with nitrogen for 10 minutes. The AIROF electrode was continuously scanned between 1.5 and $2 \mathrm{~V}$ vs. RHE at $100 \mathrm{mV} \mathrm{s}^{-1}$ for the purpose of promoting the OER under dynamic conditions. $0.75 \mathrm{ml}$ aliquots of electrolyte were taken at different time intervals. The decrease of the intensity of the absorption bands of $\mathrm{KMnO}_{4}$ in the titrating solution is proportional to the sum of the amounts of $\mathrm{H}_{2} \mathrm{O}_{2}$ present in each of the electrolyte aliquots added.

\subsection{Potential-modulated reflectance spectroscopy (PMRS)}

UV-PMR spectra were measured in a conventional three-electrode electrochemical cell equipped with fused silica windows for the entrance and exit of the light beam. The light source was a 30 W Hamamatsu L2D2 deuterium lamp. A photomultiplier tube, Model 1P28 from Hamamatsu, was used for detection. A sine potential wave $\left(\Delta \mathrm{V}=50-1000 \mathrm{mV}, f_{\mathrm{rms}}=18-729 \mathrm{~Hz}\right)$ was superimposed on the otherwise constant electrode potential and the modulated reflectance signal was detected with a digital lock-in amplifier, Stanford SR 850 DSR. The potentials were measured vs. a homemade Ag/AgCl $\left(\mathrm{KCl}_{\text {sat }}\right)$ electrode, and were then converted to the RHE scale. The spectra are plotted below using the convention that a positive sign of $\Delta R / R$ implies a lower reflectance at the positive limit of the modulation.

\section{Results and discussion}

\subsection{Flow-cell measurements}

Cyclic voltammograms of an $\mathrm{IrO}_{2}$-disc electrode recorded in the flow cell arrangement in the potential-range between 0.6 and $1.9 \mathrm{~V}$ and the corresponding Pt-ring current when held at $1.2 \mathrm{~V}$ are shown in Fig. 2. The latter potential was chosen in order to avoid oxygen reduction or oxygen evolution reaction on the ring electrode during the experiment. Thus, any current recorded at the ring electrode must correspond to electrochemical reactions involving OER intermediates emerging from the disc electrode, reactions (2) through (4), or from the generation of hydrogen peroxide, reaction (6), at the disk electrode. Both cathodic (region A) and anodic (region C) ring currents are apparent in Fig. 2.

The dependence of the disc electrode current density on the potential sweep rate is shown in Fig. 3a. As expected, the disc current density in the pseudo-capacitance region $(0.6-1.5 \mathrm{~V})$ increases with increasing sweep rate. The corresponding ring currents are shown in Fig. 3b, and also display a strong dependence on the disk-potential sweep rate.

When the disc electrode potential reaches $1.5 \mathrm{~V}$, a sharp increase in the disk current due to the onset of the OER, is apparent in Figures 2 and 3. Simultaneously, a cathodic current emerges on the ring electrode and increases as the potential of the disc electrode increases beyond 1.5 V. However, when the disc potential is reversed at $1.9 \mathrm{~V}$ there is a pronounced hysteresis in the ring current response, which increases with increasing sweep rate (at $5 \mathrm{mV} \mathrm{s}^{-1}$ there is no hysteresis), and at scan rates above $50 \mathrm{mV}$ $\mathrm{s}^{-1}$ the ring current eventually becomes positive in the reverse scan. The average disk potential at which 
the ring current becomes positive in the negative potential sweep is $1.8 \mathrm{~V}$, a maximum being reached at $1.6 \mathrm{~V}$.

Hydrogen peroxide may in principle give rise to both reduction and oxidation currents at the ring electrode, but at $1.2 \mathrm{~V}$ (the ring potential) only the oxidation of $\mathrm{H}_{2} \mathrm{O}_{2}$ is possible on Pt and no reduction current is measured [32, 33]. Therefore, the cathodic ring currents apparent in Figures 2 and 3 on the forward disk-potential scan cannot be due to the reduction of hydrogen peroxide generated as a by-product at the $\mathrm{IrO}_{2}$, and must be due to other by-products or reaction intermediates emerging from the OER.

We thus assume that the cathodic ring currents observed in Figures 2 and 3 are related to the main electrode reaction, that is to the OER and its by-products. According to Rossmeisl et al [16], the formation of S-OOH species is the potential limiting reaction at $\mathrm{IrO}_{2}$ followed by the faster formation of oxygen through reaction (5). However, for $\mathrm{IrO}_{2}$ the rate of the consecutive electrochemical reaction step, reaction (5) is not going to be very much faster as its activity appears to be only slightly larger than that of reaction (4), c. f. Fig. 6 of Ref. [16].

Therefore, hydroperoxyl $\mathrm{HOO}^{*}$ species may be assumed to be present at the surface of $\mathrm{IrO}_{2}$ to some extent. If some of this adsorbed hydroperoxyl is desorb from the electrode surface in the form of the hydroperoxyl radical $\mathrm{HO}_{2}$ instead of forming oxygen through reaction (5), these may in principle be reduced at the ring according to the following reactions [24, 25]:

$\mathrm{HO}_{2}+3 \mathrm{H}^{+}+3 e^{-} \rightarrow 2 \mathrm{H}_{2} \mathrm{O} \quad \mathrm{E}^{0}=1.65 \mathrm{~V}$

$\mathrm{HO}_{2}+\mathrm{H}^{+}+e^{-} \rightarrow \mathrm{H}_{2} \mathrm{O}_{2} \quad \mathrm{E}^{\circ}=1.44 \mathrm{~V}$

However, rate constants for recombination of the hydroperoxy species to hydrogen peroxide are in the order of $10^{6} \mathrm{M}^{-1} \mathrm{~s}^{-1}$ [24]. The time expected for the radicals to reach the ring electrode in RRDE experiments would be in the order of ms [34]. The flow conditions employed here are not as well defined as in an RRDE experiment, but the maximum electrolyte velocity out of the orifice in our experiments is $0.2 \mathrm{~m} \mathrm{~s}^{-1}$. The time it will take the electrolyte to traverse the distance between the disk and the ring of the ring-disc electrode is therefore also at least in the order of a few ms. It is thus highly unlikely that a significant portion of the hydroperoxy radicals would reach the ring before recombination. However, as the hydrogen peroxide will not give rise to a cathodic current at the ring, other possibilities will have to be considered. Hydroperoxyl may, however, also recombine to ozone [25], the thermodynamic potential for the electrochemical formation of which is $1.51 \mathrm{~V}$ [25, 35]. In an alkaline solution ozone decomposition is triggered by a direct reaction between $\mathrm{O}_{3}$ and $\mathrm{OH}^{-}$[.36]. At low $\mathrm{pH}$, and if ions such as $\mathrm{I}^{-}, \mathrm{NO}_{2}{ }^{-}, \mathrm{Fe}^{2+}$, and $\mathrm{Mn}^{2+}$ are not present in the solution, we expect ozone to be more stable [37]. Ozone and may thus be reduced at the ring at Pt electrodes even at very low concentrations [38]. The current response of an amperometric gas sensor containing $0.5 \mathrm{M} \mathrm{H}_{2} \mathrm{SO}_{4}$ as the electrolyte to air containing ozone in concentrations as low as $1 \mathrm{ppm}$ is in the order of $\mathrm{nA}$ at $1.2 \mathrm{~V}$ 
vs the standard hydrogen electrode at Pt electrodes [38]. However, although this illustrates the possibility of ozone reduction at the Pt ring, the value of comparison with gas sensors is limited since the actual concentration of ozone in the aqueous phase in these gas sensors is unknown. Beyond the indication that the cathodic current at the ring is related to intermediates of the OER or products of the reactions of these intermediates, our results therefore remain inconclusive on this point.

As explained above, at $1.2 \mathrm{~V}$ any $\mathrm{H}_{2} \mathrm{O}_{2}$ formed on the $\mathrm{IrO}_{2}$ disc electrode and reaching the $\mathrm{Pt}$ ring can only be oxidized. This is the only reaction that can produce an anodic current at the ring at the potential employed. The ring current strongly depends on the sweep rate of the disc electrode. Application of potential sweep rates higher than $25 \mathrm{mV} \mathrm{s}^{-1}$ to the disc electrode leads to the appearance of an anodic peak on the ring electrode in the reverse scan at a disc potential of $1.6 \mathrm{~V}$ (Fig. 3b). Therefore, we attribute the positive ring current at disk potentials between 1.8 and $1.1 \mathrm{~V}$ in the negative-going sweep (Region $\mathrm{C}$ of Fig. 2) to the oxidation of hydrogen peroxide accumulated on the $\mathrm{IrO}_{2}$ disc at potentials of approximately $1.8 \mathrm{~V}$. At scan rates less than $25 \mathrm{mV} \mathrm{s}^{-1}$, hydrogen peroxide is oxidized on the disc before reaching the ring. Thus, these measurements identify two loss processes for the OER at iridium oxide electrodes: the desorption of intermediate species and the formation of hydrogen peroxide.

The ring peak amplitude, and, hence, the net amount of byproduct of the OER generated, increases linearly with the disc potential sweep rate, as shown on the insert of Fig. 3b. This is consistent with the fact that OER is more efficient at low potential sweep rates, and suggests that, at fast scan rates, the potential is reversed before all the $\mathrm{HO}_{2}$ and $\mathrm{H}_{2} \mathrm{O}_{2}$ formed on the disc can be further oxidized to $\mathrm{O}_{2}$. In other words, under dynamic potential load the OER will be less efficient. Therefore, if water electrolyzers with $\mathrm{IrO}_{2}$ anodic catalysts are to be integrated with intermittent power sources, it is important to have power stabilization in order to suppress, or at least minimize, generation of the corrosive OER by-products.

Cyclic voltammograms for $\mathrm{IrO}_{2}$ and $\mathrm{Ir}_{0.6} \mathrm{Ru}_{0.4} \mathrm{O}_{2}$ electrodes are shown in Fig. 4. The voltammogram for the $\mathrm{Ir}_{0.6} \mathrm{Ru}_{0.4} \mathrm{O}_{2}$ has some pronounced features which are different from those of $\mathrm{IrO}_{2}$ and can be attributed to ruthenium oxide, namely a large cathodic current at potentials between 0 and $0.2 \mathrm{~V}$, absent in iridium oxide.

The activity of the catalysts towards oxygen evolution was measured also for an $\operatorname{Ir}_{0.6} \mathrm{Ru}_{0.4} \mathrm{O}_{2}$ catalyst with the flow-cell RDE, and the activity of this electrode for the OER is compared to that of the pure $\mathrm{IrO}_{2}$ as shown in Fig. 5. (The polarization curves were recorded with a sweep rate of $5 \mathrm{mV} \mathrm{s}^{-1}$. Although this paper does not deal with an analysis of Tafel plots as such, we demonstrate the compliance of the data with the Tafel equation Fig. 6, which shows the data collected disk data for $\mathrm{IrO}_{2}$ with and without compensation for ohmic drops and the difference between the IR-corrected data and the raw data. The compensation was performed according to the method in Ref. [8]). If properly IR-corrected the difference between the IR-corrected data and the raw data should form a straight line passing through 
the origin, which it appears to do. The uncompensated resistance is estimated to $5.4 \Omega \mathrm{cm}^{2}$ for the data in Fig. 6. Both catalysts have qualitatively similar catalytic behavior, but the current attributed to oxygen evolution on iridium oxide is shifted slightly towards higher potentials (about $20 \mathrm{mV}$ ) than on $\mathrm{Ir}_{0.6} \mathrm{Ru}_{0.4} \mathrm{O}_{2}$, as expected.

The corresponding ring currents are shown in Fig. 6. The shapes of the ring electrode current response are significantly different for $\operatorname{IrO}_{2}$ and $\mathrm{Ir}_{0.6} \mathrm{Ru}_{0.4} \mathrm{O}_{2}$. (The differences in noise levels in Fig. 8 are related to the potentiostat settings in these two particular experiments. However, the experiments were reproduced several times with similar results.) For both compositions there is a pronounced cathodic current which starts at the potentials of oxygen evolution reaction. This can be related to the reduction of reaction intermediates, as discussed above. However, the pronounced anodic peak that appears in the negative potential sweep at high scan rates with the iridium oxide electrode is absent for the $\mathrm{Ir}_{0.6} \mathrm{Ru}_{0.4} \mathrm{O}_{2}$ electrode. Another significant difference is that, while the ring current amplitude multiplies by a factor of four when the scan rate increases from 5 to $100 \mathrm{mv} \mathrm{s}^{-1}$ in the case of the $\mathrm{IrO}_{2}$, in the case of the $\mathrm{Ir}_{0.6} \mathrm{Ru}_{0.4} \mathrm{O}_{2}$ it just doubles.

This difference suggests that a smaller amount of soluble byproducts is produced on $\mathrm{Ir}_{0.6} \mathrm{Ru}_{0.4} \mathrm{O}_{2}$. There are two possible explanations for the reduced amount of byproduct formed on ruthenium-doped iridium oxide. On one hand, assuming a mononuclear mechanism for the OER and that both iridium and ruthenium in the oxide structure behave as independent active sites, two kinds of active sites, oxygen-surrounded ruthenium and oxygen-surrounded iridium, exist. Assuming that the bonding of intermediates is weaker on the ruthenium sites than on the iridium sites and, hence, oxygen evolution is more favorable, in the absence of any synergetic effect between the two types of catalytic sites substitution of $40 \%$ of iridium atoms with ruthenium should enhance oxygen evolution activity and suppress side products formation by $40 \%$. For the same catalysts loading, the increase in the ring current amplitude, due to the formation of the OER byproducts, is 1.5 times larger for $\mathrm{IrO}_{2}$ than for $\mathrm{Ir}_{0.6} \mathrm{Ru}_{0.4} \mathrm{O}_{2}$, which correlates well with having substituted $40 \%$ of the iridium atoms by ruthenium. On the other hand, OER can occur according to a binuclear mechanism. Introduction of homogeneously distributed ruthenium atoms into iridium oxide matrix can, therefore, suppress the OER byproducts formation, because the reaction step (5) would be favored on the $\mathrm{Ir}-\mathrm{Ru}$ or $\mathrm{Ru}$ - Ru bridge sites due to weaker adsorption of the reaction intermediates. However, in this case information about the relative rates of the reaction steps is yet not available, and reaching a conclusion is not possible.

The differences in efficiency with respect to oxygen formation must be related to the various rate constants of the reactions involved (rate constants for desorption of hydroperoxyl, its recombination etc.). These would, in turn, be functions of the coverage and be related to the binding energies at the specific catalytic material employed. Significant suppression of cathodic current and disappearance of the anodic current on the back scan for Ru-doped iridium oxide is presumably related to different binding energies and rate limiting steps of the OER for $\mathrm{IrO}_{2}$ and $\mathrm{RuO}_{2}$. For example, at $\mathrm{IrO}_{2}$ the rate-limiting 
step is expected to be formation of the $\mathrm{HOO}^{*}$ intermediate (reaction (4)) whereas at $\mathrm{RuO}_{2}$ the formation of the $\mathrm{O}^{*}$ intermediate is the rate-limiting step. However, according to Ref. [16] the consecutive reactions at $\mathrm{RuO}_{2}$ have a much higher catalytic activity for the steps leading to the eventual evolution of oxygen than at $\mathrm{IrO}_{2}$. The presence of $\mathrm{HOO}^{*}$ intermediates may therefore be less pronounced at $\mathrm{RuO}_{2}$ than at $\mathrm{IrO}_{2}$, per se reducing the likelihood that it desorbes before it is oxidised further to give oxygen. On the other hand, HOO* is less strongly bound to the surface at $\mathrm{RuO}_{2}$, which should increase its presence in solution. The actual evaluation therefore depends on parameters beyond which we were able to obtain in this study. However, since high-overpotential oxygen overvoltage materials are needed for the production of by-products of the OER such as ozone [39], the higher the overvoltage for the OER the larger the amount of byproduct would one expect. This is, in fact, consistent with the experiments performed here.

\subsection{UV-Vis measurements}

In order to provide further indications of the formation of hydrogen peroxide as a byproduct of oxygen evolution, the evolution of $\mathrm{UV}-\mathrm{V}$ is of a $\mathrm{KMnO}_{4}$ solution during OER at high overpotentials was followed (Fig. 8).

There is a clear decrease in the intensity of the absorption band of $\mathrm{MnO}_{4}{ }^{-}$when successive aliquots of solution taken from the electrolytic cell during intensive oxygen evolution are added to the initial $0.17 \mathrm{~mm} \mathrm{KMnO}_{4}$ solution, which is a clear evidence of the formation of hydrogen peroxide as a byproduct of the OER. The time evolution of absorbance at $522 \mathrm{~nm}$ is shown in Fig. 9. The peak intensity is rapidly decreasing during OER. This behavior can be explained by the continuous generation of the hydrogen peroxide as a side product of the OER, which is reacting with potassium permanganate with forming of transparent $\mathrm{Mn}^{2+}$ species.

Dynamic conditions, rather than steady state electrolysis were utilized in order to enhance the (intermittent) formation of reaction by-products and intermediates during the anodic reaction as much as possible, c. f. the discussion above. Consequently, we have refrained from attempting to estimate the amount of byproducts or hydrogen peroxide and correlate these with the amount of permanganate being reduced in the solution.

\subsection{PMRS}

Spectroscopic techniques can be useful in the identification of the reaction intermediates. However, infra-red spectroscopy, which is commonly used for the intermediates identification is limited for this particular case due to overlapping of the signals from electrolyte and adsorbed species. Potential modulated reflectance spectroscopy (PMRS) can give some insights for the adsorbed intermediates identification. PMRS detects changes in the reflectance of a surface due to variations in the potential drop across the interface. Since the potential profile in the bulk phases on both sides of the interface is flat, it is extremely sensitive to the interfacial region, where the potential drop occurs. In the case of a 
metal-electrolyte interface, this will comprise the Thomas-Fermi length within the metal (typically some fractions of an $\AA$, i.e., a penetration depth of less than an atomic layer) and the electrolyte side of the double layer. In the case of a semiconductor-electrolyte interface, the region probed by PMRS will include the semiconductor's space-charge region and the electrolyte side of the double layer. In the particular case studied here, PMRS will provide information on a considerable fraction of the AIROF and on the electrolyte's interfacial region. The features arising in PMR spectra can be due to purely physical effects (changes in reflectance due to the alteration of the dielectric constant of the electrode's surface when the surface charge density changes, the so-called electroreflectance, ER), to chemical changes on the interface (changes in the chemical nature of the electrode surface or of the species present in the double layer) or to a combination of both. Therefore, PMRS is potentially well suited for the identification of OER intermediates.

PMRS experiments (as any other reflection spectroscopy technique) require surfaces with a high enough reflectivity, and for this reason we used iridium oxide films grown on Ir rather than the nanostructured catalysts employed above. Although structure and size effects cannot be discarded completely, we have shown previously that the charge-normalised polarization curves for the OER are virtually indistinguishable [40]. Also, the cyclic voltammograms of the two materials display much the same redox processes, so we assume that the PMRS results obtained with the AIROFs can be extrapolated also to the nanoparticulate material.

PMRS has been applied to the study of anodically formed iridium oxide (AIROF) with the aim of identifying the electrochemical reactions involved in its electrochromic process [30, 41]. The latter has been postulated to correspond to the oxidation of a transparent, insulating Ir(III) oxyhydroxide to a blue-black, conducting Ir(IV) oxyhydroxide [42]. This electrochromic process is believed to involve a simple solid-state mechanism, in which the application of a positive enough anodic potential decreases the Fermi level of the AIROF from the top of the conduction band of $\mathrm{IrO}_{2}$ (transparent, insulating state) to its interior (blue-black, conducting state).

AIROF is a p-type semiconductor at potentials below $0.6 \mathrm{~V}$ vs. RHE, however above $0.8-1$ $\mathrm{V}$ it becomes a conductor [40]. Therefore, significant changes in its reflectance are to be expected in this potential region. Further relevant changes in the electronic structure of the AIROF are not expected until $1.3 \mathrm{~V}$, where an anodic peak usually appears in the corresponding cyclic voltammograms. This peak is usually attributed to the oxidation of the $\mathrm{IrO}_{2}(\mathrm{OH})$ to $\mathrm{IrO}_{3}$ with $\mathrm{Ir}$ in hexavalent state [43]. At potentials higher than $1.3 \mathrm{~V}$ no pronounced changes in the electronic structure of the AIROF are expected and the ER is expected to be very small. Accordingly, at the very positive potentials used in this work, bands in PMR spectra can be related to the production of intermediates of the OER.

Fig. 10 shows PMR spectra between 200 and $400 \mathrm{~nm}$ of an AIROF electrode in $0.5 \mathrm{M} \mathrm{HClO}_{4}$ obtained with a frequency of $63 \mathrm{~Hz}$ and different potential amplitudes. The positive limit of the 
modulation was restricted by the occurrence of extensive oxygen evolution, where PMR spectra became noisy due to the scattering of light by oxygen bubbles. Three different negative limits for the potential modulation were used: $0.744 \mathrm{~V}$ (Fig. 10a), $1.244 \mathrm{~V}$ (Fig. 10b) and $1.444 \mathrm{~V}$ (Fig. 10c) in order to determine the potential range of intermediate species formation. There are two features common to all the spectra in Fig. 10, except those in which the potential was modulated between $0.744 \mathrm{~V}$ and $\mathrm{E}<1.744$ V: a maximum at $200 \mathrm{~nm}$ and a broad peak between 250 and $350 \mathrm{~nm}$.

For a negative limit of the modulation of $0.744 \mathrm{~V}$, the sign of the peak at $200 \mathrm{~nm}$ changes from negative to positive when the positive limit of the modulation increases from 1.344 to $1.744 \mathrm{~V}$. Concomitantly, a new broad peak between 250 and $350 \mathrm{~nm}$ appears. In the region between 210 and 230 $\mathrm{nm}$, a peak appears when the negative limit of the modulation is $1.244 \mathrm{~V}$ and the positive limit is above $1.644 \mathrm{~V}$, as well as in all the spectra with a negative modulation limit of $1.444 \mathrm{~V}$.

The fact that iridium oxide is electrochromic implies that light absorption in its dark form must contribute to the PMRS spectra. This contribution appears only when the positive limit of the potential modulation is well within the region in which the film is in its oxidized form, because, as shown by Gottesfeld et al. [30], coloration of the film at $1.244 \mathrm{~V}$ vs. RHE takes approximately $40 \mathrm{~ms}$. This is approximately one order of magnitude larger than the oscillation period in our experiments $(1 / 63 \mathrm{~Hz})$. The broad peak between 250 and $350 \mathrm{~nm}$ coincides with that observed by Gottesfeld et al. [30] and is due to this well-known electrochromism. No electrochromism is observed when the negative limit of the modulation is below the peak corresponding to the oxidation of the oxide film and the positive potential limit is below $1.74 \mathrm{~V}$ (black and red lines in Fig. 10a). When the negative potential limit is positive of the oxidation peak (Fig. 10b) the intensity of this signal is smaller because part of the oxide film is already in its oxidised form at the negative limit of the modulation, and it saturates when the positive potential limit is such that all the film is in its oxidised form (red, blue, and green lines in Fig. 10b).

However, the signal at $200 \mathrm{~nm}$ continues increasing even when the signal due to the film's electrochromism has saturated. Similarly, the signal between 210 and $230 \mathrm{~nm}$ only appears when the electrochromism signal saturates. This, together with the fact that their appearance coincides with the onset of oxygen evolution, indicates that they are not due to any electrochromic effect.

Also, changes in the dielectric constant of the electrolyte side of the double layer when the potential changes must contribute to changes in the reflectivity. However, if there is no singularity in the wavelength-dependence of the refractive index (n) and the extinction coefficient (k), this will simply result in a shift of the baseline. (This is what happens, for example, in IR reflectance spectroscopy, where an effect of the interfacial water can only be observed around the frequencies corresponding to the water stretching (broad band around $3000 \mathrm{~cm}^{-1}$ ) and bending modes (around $1650 \mathrm{~cm}^{-1}$ ), at which both $\mathrm{n}$ and $\mathrm{k}$ change abruptly.) In the ultraviolet region in our measurements neither $\mathrm{n}$ nor $\mathrm{k}$ show any 
abrupt change. Only at wavelengths close to $200 \mathrm{~nm}$ is there a sudden increase, which might be the cause for the signal observed around $200 \mathrm{~nm}$ in the spectra in Figures 10 and 12. At longer wavelengths, however, the change in the dielectric constant of water will at most provoke a shift in the baseline. Therefore, we interpret the signal between 210 and $230 \mathrm{~nm}$ as corresponding to an intermediate in the OER.

In order to confirm that the peaks observed in the PMR spectra are due to species generated during the OER and not to an ER effect, their dependence on both the modulation amplitude and the modulation frequency was analyzed. Electrolyte electroreflectance (EER) signals increase linearly with the modulation amplitude and are independent of the modulation frequency. On the contrary, if the PMR signal is due to the production or depletion of a chemical species, its intensity will usually increase with the modulation amplitude (more species will be produced in the same time interval if the overpotential is higher), albeit not necessarily linearly, and it will decrease with increasing frequency (the time during which the electrode is at a potential at which the species is formed or consumed will decrease with increasing frequency). Furthermore, EER peaks typically shift with a shift of the central potential.

As shown in Fig. 11, the intensity of all the peaks increases with increasing modulation amplitude, but except in the case of peak at $200 \mathrm{~nm}$, the dependence is not linear. Furthermore, the intensity of the peaks decreases clearly with increasing modulation frequency (Fig. 12), and the peak position does not show any clear shift with the electrode potential. The sign on the PMR bands indicates a decrease of the electrode reflectance at the positive limit of the modulation, which can be reasonably attributed to the absorption of light by new chemical species formed during the OER. . As indicated above, the broad peak between 250 and 350 nm coincides with that observed by Gottesfeld et al. [30] and is due to the electrochromism of iridium oxide. The intense signal at wavelengths below $210 \mathrm{~nm}$ coincides with a relatively sudden increase of the refractive index ( $n$, the real part of the complex refraction index, $\hat{n}$ ) of water, and is, hence, most likely due to a change in the dielectric constant of water with potential. This is in agreement with the linear dependence of its intensity on the modulation frequency, since the degree of dipole alignement (i.e., of dielectric saturation), must also depend roughly linearly on the intensity of the interfacial electric field. However, the signal observed between 210 and $230 \mathrm{~nm}$ cannot be explained by any of these contributions, and must therefore be due to reaction intermediates generated during the OER at the positive limit of the potential modulation.

According to theoretical calculations [16], the surface of iridium is covered with $\mathrm{O}^{*}$ at potentials above $1.244 \mathrm{~V}$, which transforms to ${ }^{*} \mathrm{OOH}$ species at more positive potentials. Candidates for the species responsible for the PMRS peak at $220 \mathrm{~nm}$ were identified based on the analysis of the available absorption cross section's data [44]. The hydroperoxy radical $\mathrm{HO}_{2}$ is the only possible intermediate which exhibits an absorption peak around $210 \mathrm{~nm}$ in aqueous solution. A shift to $220 \mathrm{~nm}$ can be explained by its interaction with the electrode surface. This might be, hence, the first experimental evidence of the formation of $\mathrm{HO}_{2}$ as an intermediate of the OER. 


\section{Conclusions}

The formation of side products of the OER, which we suggest to be the potentially corrosive $\mathrm{HO}_{2}$ and $\mathrm{H}_{2} \mathrm{O}_{2}$, was detected at iridium oxide electrodes. These products are known to be strong oxidizing agents and can lead to the corrosion of the electrode material and of the Nafion membrane. These species were identified by combining measurements in a flow-cell employing a stationary ringdisc electrode, UV-VIS spectroscopy and PMRS.

OER byproducts are generated both by charge transfer reactions and by the chemical recombination and desorption of intermediates adsorbed on the electrode surface. The rate of generation of these by-product species depends on the operational conditions and is favored by potentiodynamic conditions. Therefore, if water electrolyzers are to be integrated with intermittent energy sources, short term power stabilization is required in order to obtain quasi-steady state operational regimes for the electrolyzer, thus reducing the amount of detrimental byproducts.

Anodic generation of byproducts may also be suppressed by proper catalyst design. By optimizing catalyst composition according to its $\mathrm{OOH}^{*}$ and $\mathrm{O}^{*}$ binding energies and oxygen evolution activity, the $\mathrm{H}_{2} \mathrm{O}_{2} / \mathrm{O}_{2}$ ratio may be adjusted in order to suppress unwanted side reactions. We demonstrated this with a catalyst with the composition $\operatorname{Ir}_{0.6} \mathrm{Ru}_{0.4} \mathrm{O}_{2}$, at which the amount of by-products was substantially reduced.

\section{Acknowledgment}

This work was supported by the Research Council of Norway under project No. 10344000. 


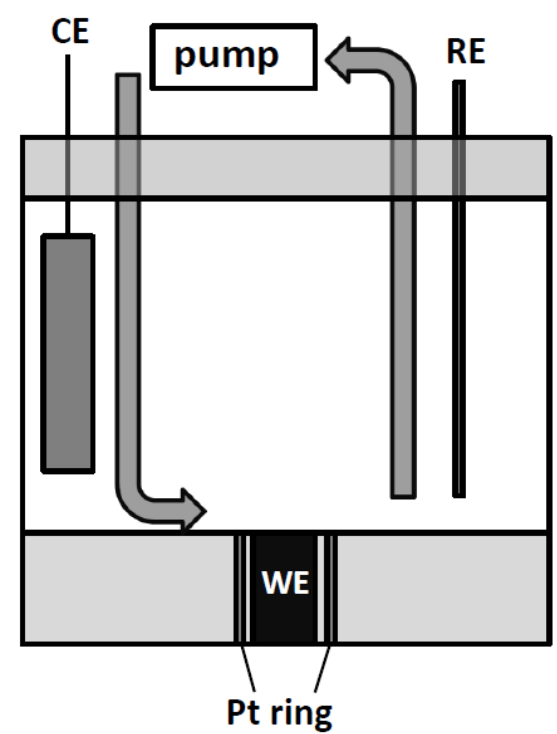

Fig. 1 Schematic of the flow cell arrangement

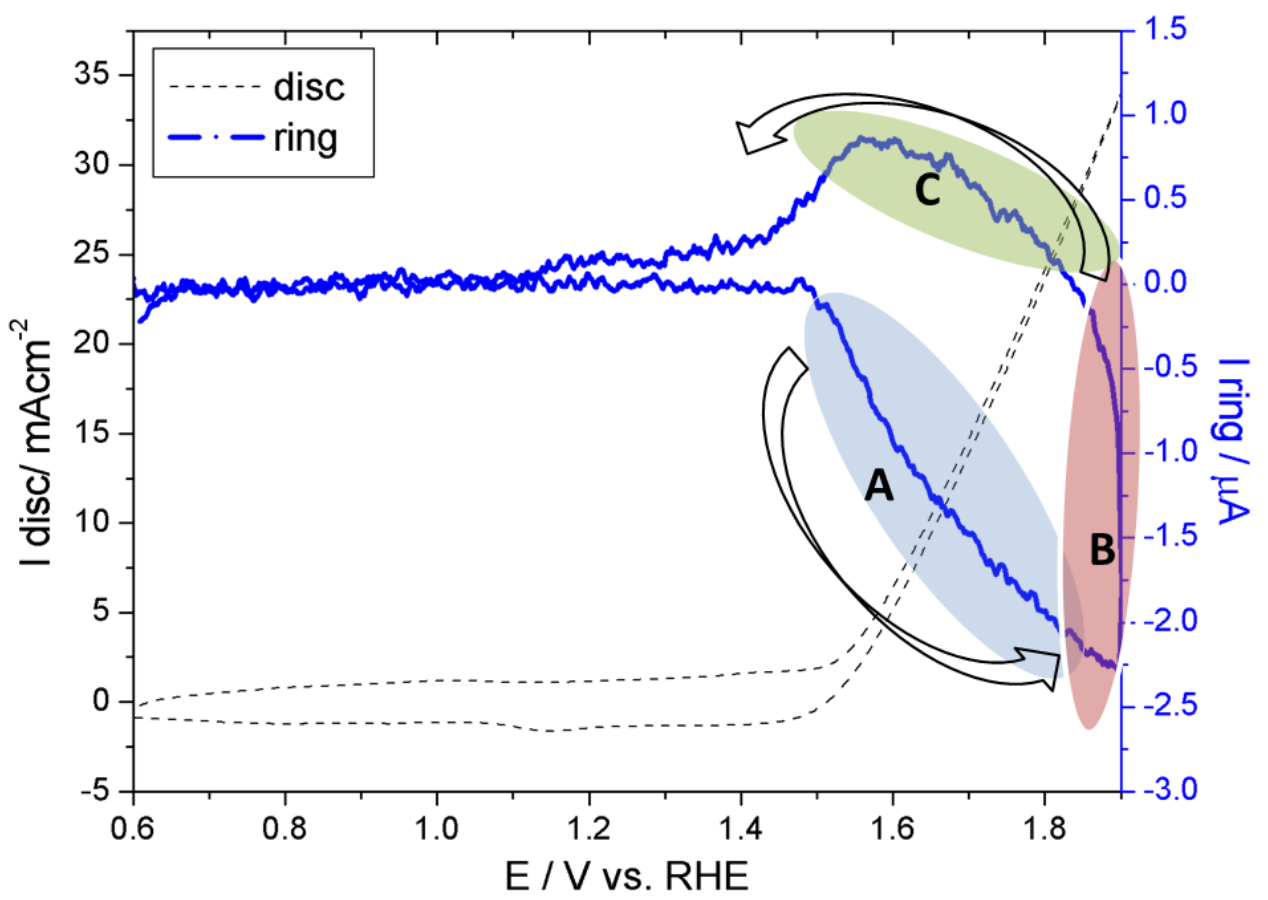

Fig. 2 Cycling voltammogram of an $\mathrm{IrO}_{2}$-disc/Pt-ring electrode in $\mathrm{N}_{2}$-saturated $0.5 \mathrm{M} \mathrm{H}_{2} \mathrm{SO}_{4}$ solution. The Pt ring was held at constant potential 1.2 V. The disc electrode was scanned at a 100 $\mathrm{mV} / \mathrm{s}$. Flow cell arrangement, pump rate $300 \mathrm{ml} / \mathrm{min}$. Highlighted areas are explained in the text 


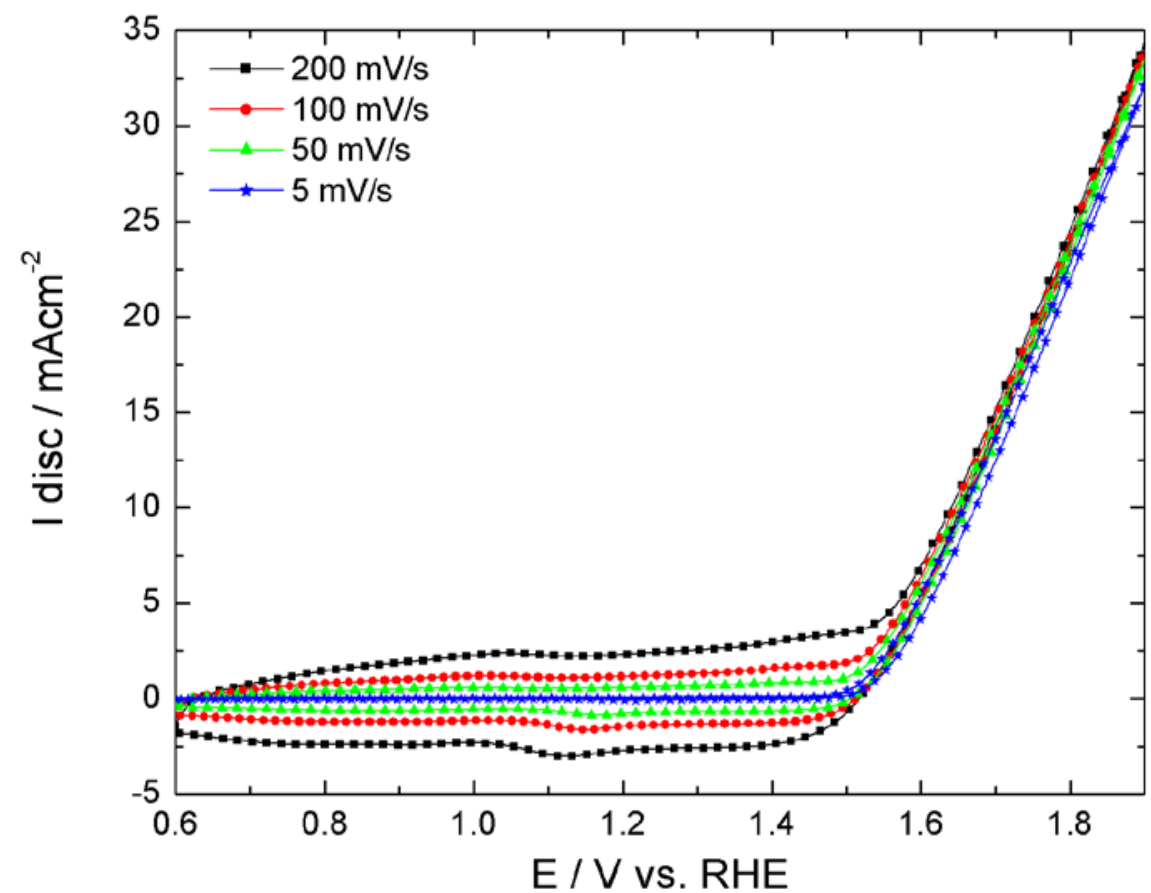

Fig. 3a Cyclic voltammograms for $\mathrm{IrO}_{2}$ disc electrode in $\mathrm{N}_{2}$-saturated $0.5 \mathrm{M} \mathrm{H}_{2} \mathrm{SO}_{4}$ between 0.6 and $1.9 \mathrm{~V}$ vs. RHE at different sweep rates.

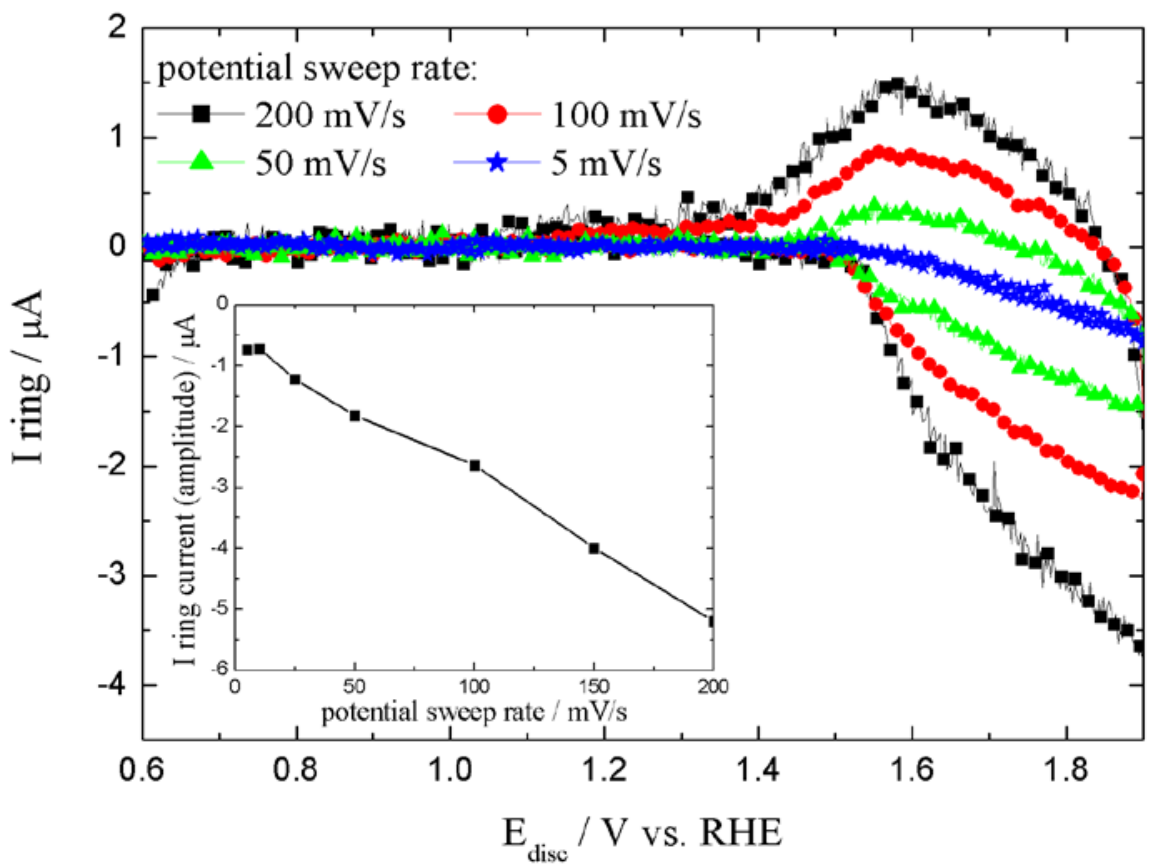

Fig. 3b Platinum ring-electrode current response in $\mathrm{N}_{2}$-saturated $0.5 \mathrm{M} \mathrm{H}_{2} \mathrm{SO}_{4}$ during scanning of the $\mathrm{IrO}_{2}$ disc electrode from 0.6 to $1.9 \mathrm{~V}$ vs. RHE at different sweep rates. The ring was held at a constant potential of $1.2 \mathrm{~V}$. The dependence of the ring current amplitude (minimum current minus maximum current) on the sweep rate is shown in the insert. 


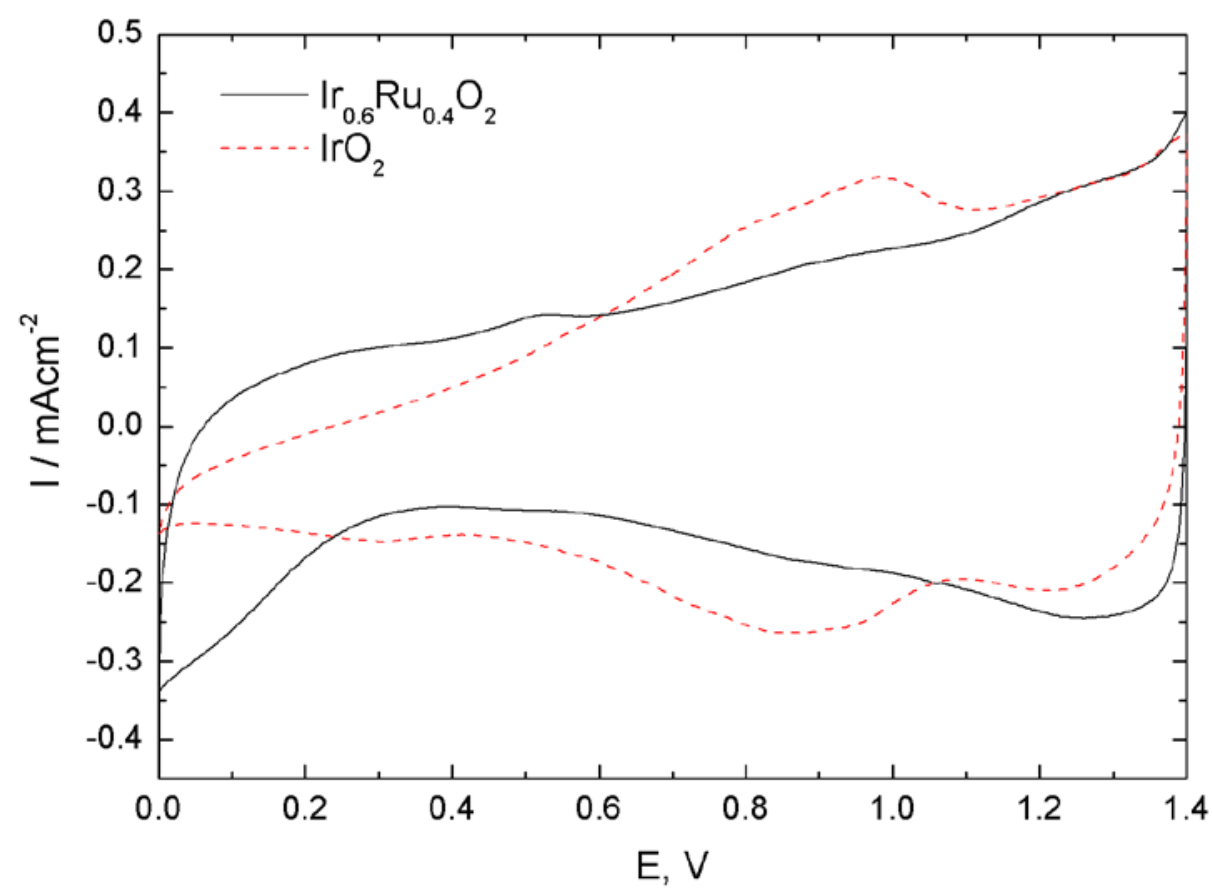

Fig. 4 Cyclic voltammograms for $\operatorname{IrO}_{2}$ and $\mathrm{Ir}_{0.6} \mathrm{Ru}_{0.4} \mathrm{O}_{2}$ electrodes in $\mathrm{N}_{2}$-saturated $0.5 \mathrm{M} \mathrm{H}_{2} \mathrm{SO}_{4}$. Sweep rate $20 \mathrm{mV} / \mathrm{s}$

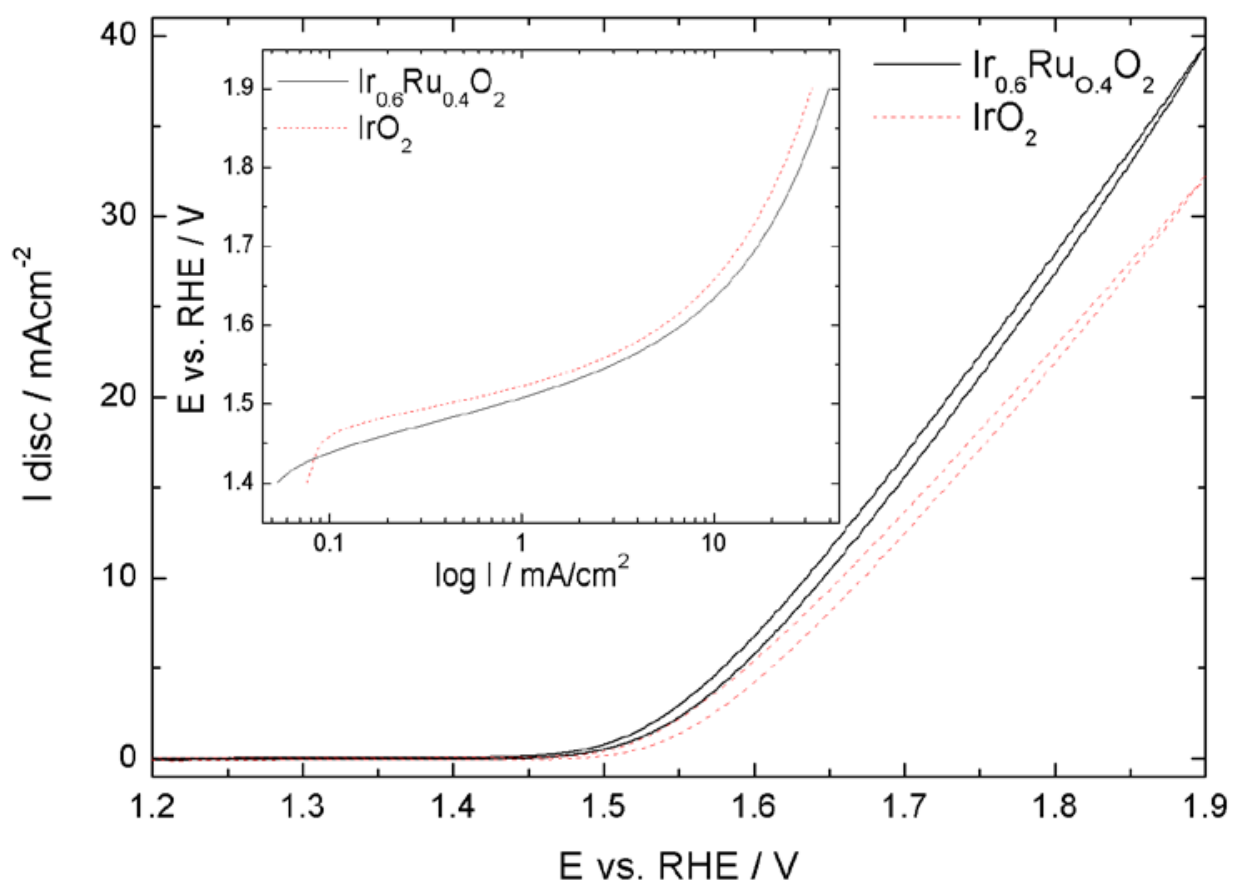

Fig. 5 Current-potential curves for $\mathrm{IrO}_{2}$ and $\mathrm{Ir}_{0.6} \mathrm{Ru}_{0.4} \mathrm{O}_{2}$ recorded in $0.5 \mathrm{M} \mathrm{H}_{2} \mathrm{SO}_{4}$. The current was normalized with respect to the geometric area of the electrode. Sweep rate $5 \mathrm{mV} / \mathrm{s}$. Insert: Tafel plots for $\mathrm{IrO}_{2}$ and $\mathrm{Ir}_{0.6} \mathrm{Ru}_{0.4} \mathrm{O}_{2}$ 

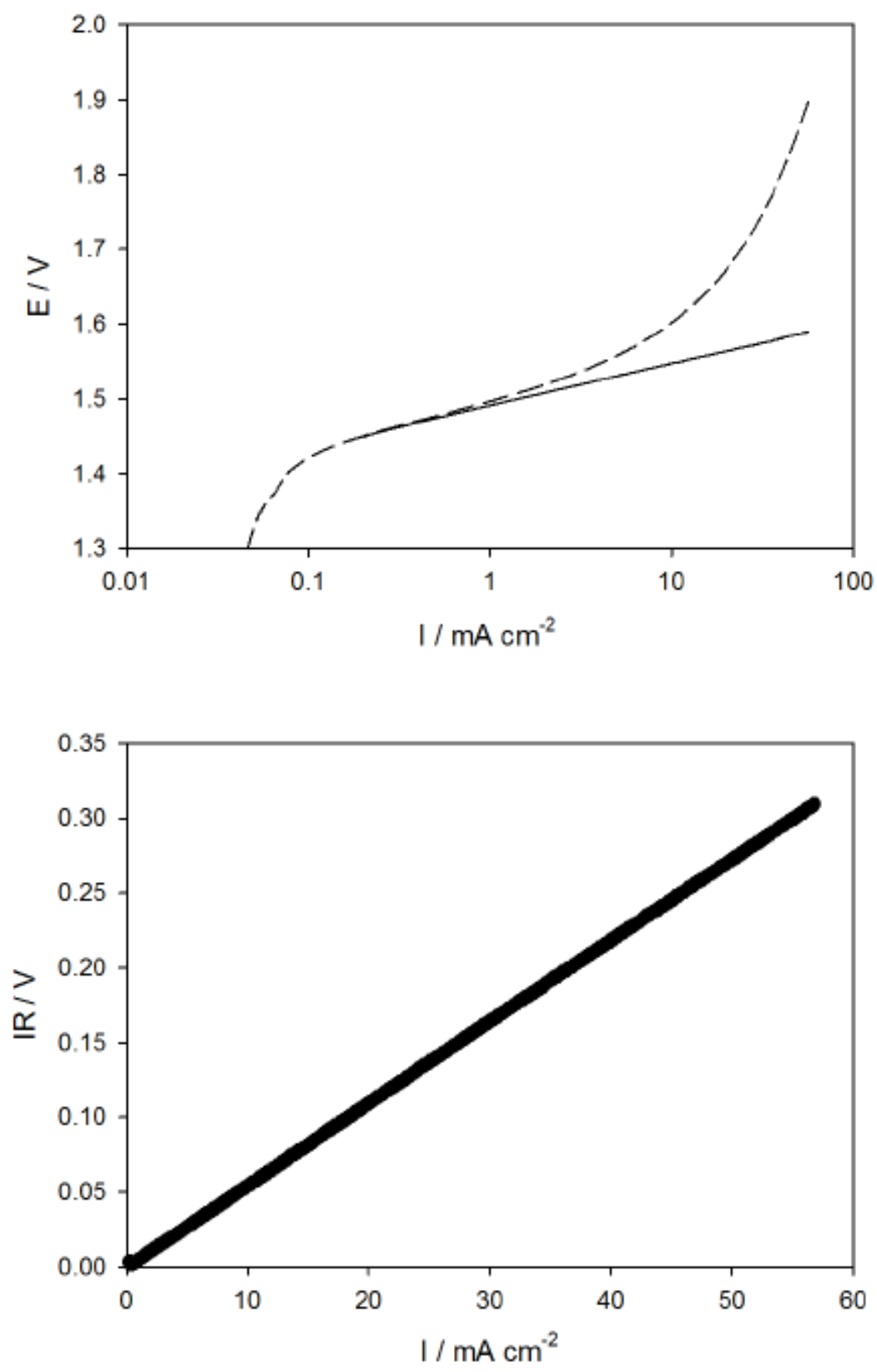

Fig. 6 Top: Uncompensated potential and potential compensated for ohmic drops as a function of current density for $\mathrm{IrO}_{2}$. Bottom: Difference between raw potential and the potential corrected for ohmic drop as a function of current density for $\mathrm{IrO}_{2}$. 


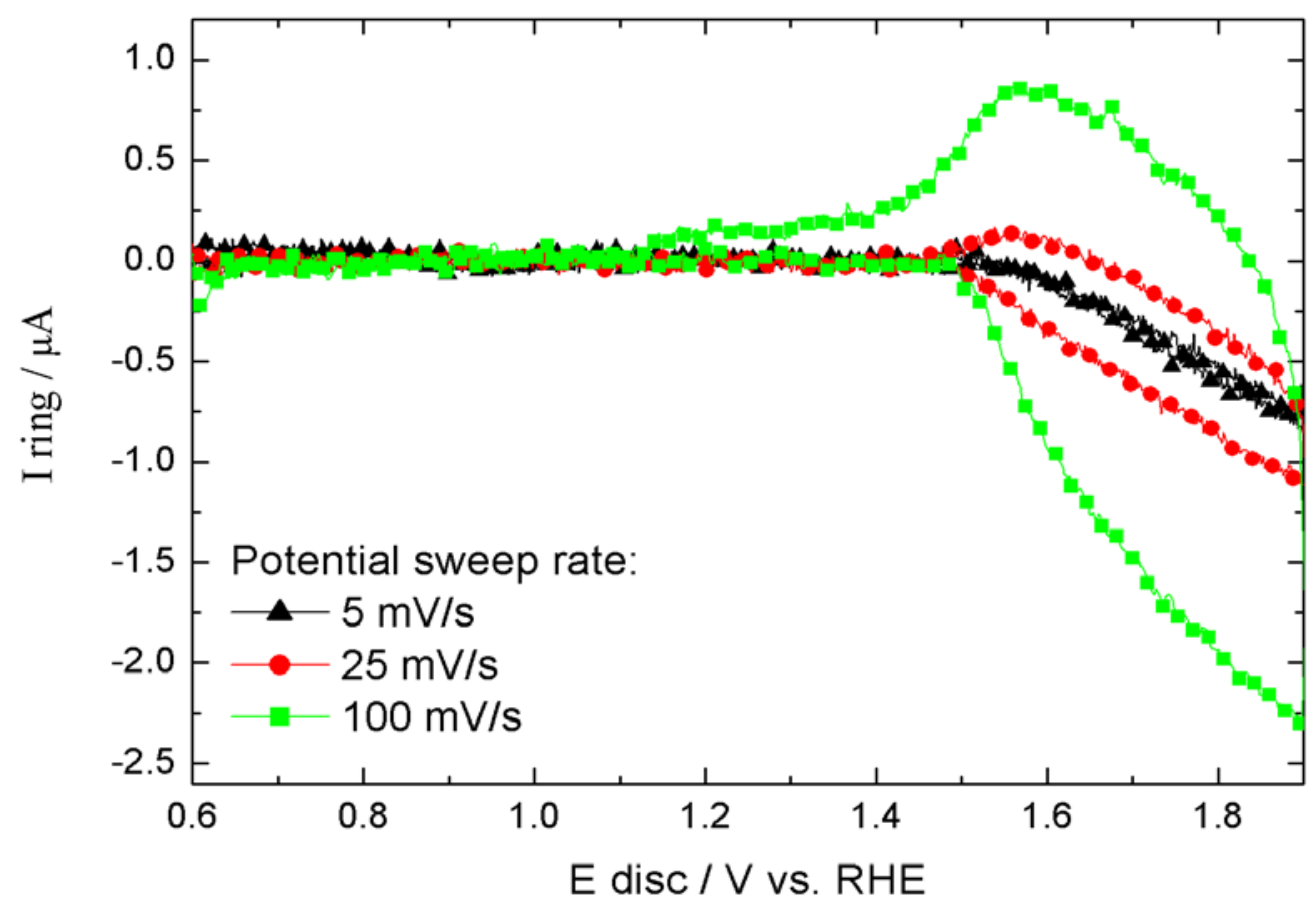

a

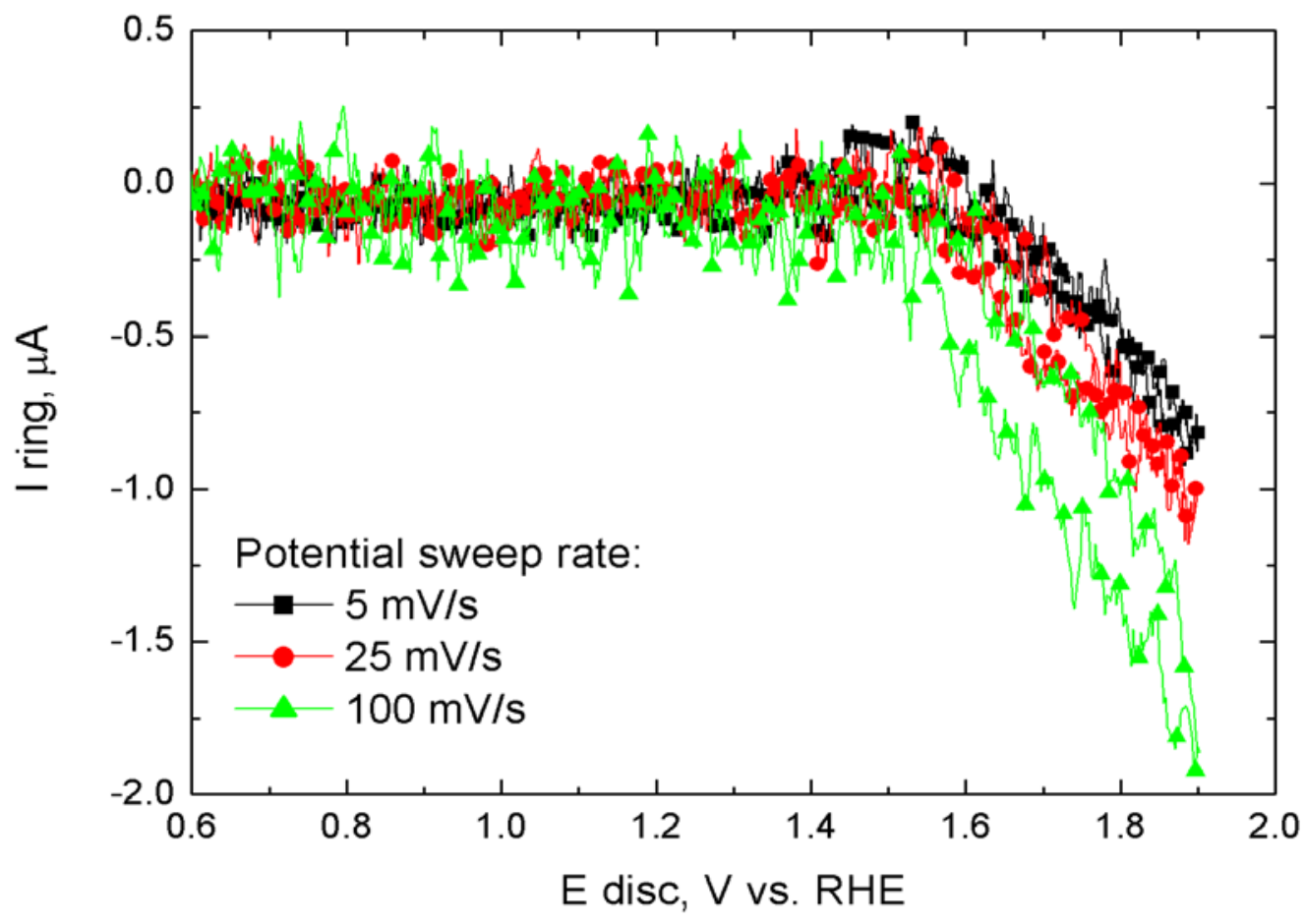

b

Fig. 7 Comparison of the Pt-ring electrode current response in $\mathrm{N}_{2}$-saturated $0.5 \mathrm{M} \mathrm{H}_{2} \mathrm{SO}_{4}$ during scanning of the disc electrode between 0.6 to $1.9 \mathrm{~V}$ at different potential sweep rates. $\mathrm{Pt}$ - ring electrode was held at $1.2 \mathrm{~V}$. Disc electrode composition: a) $\mathrm{IrO}_{2}$ b) $\mathrm{Ir}_{0.6} \mathrm{Ru}_{0.4} \mathrm{O}_{2}$ 


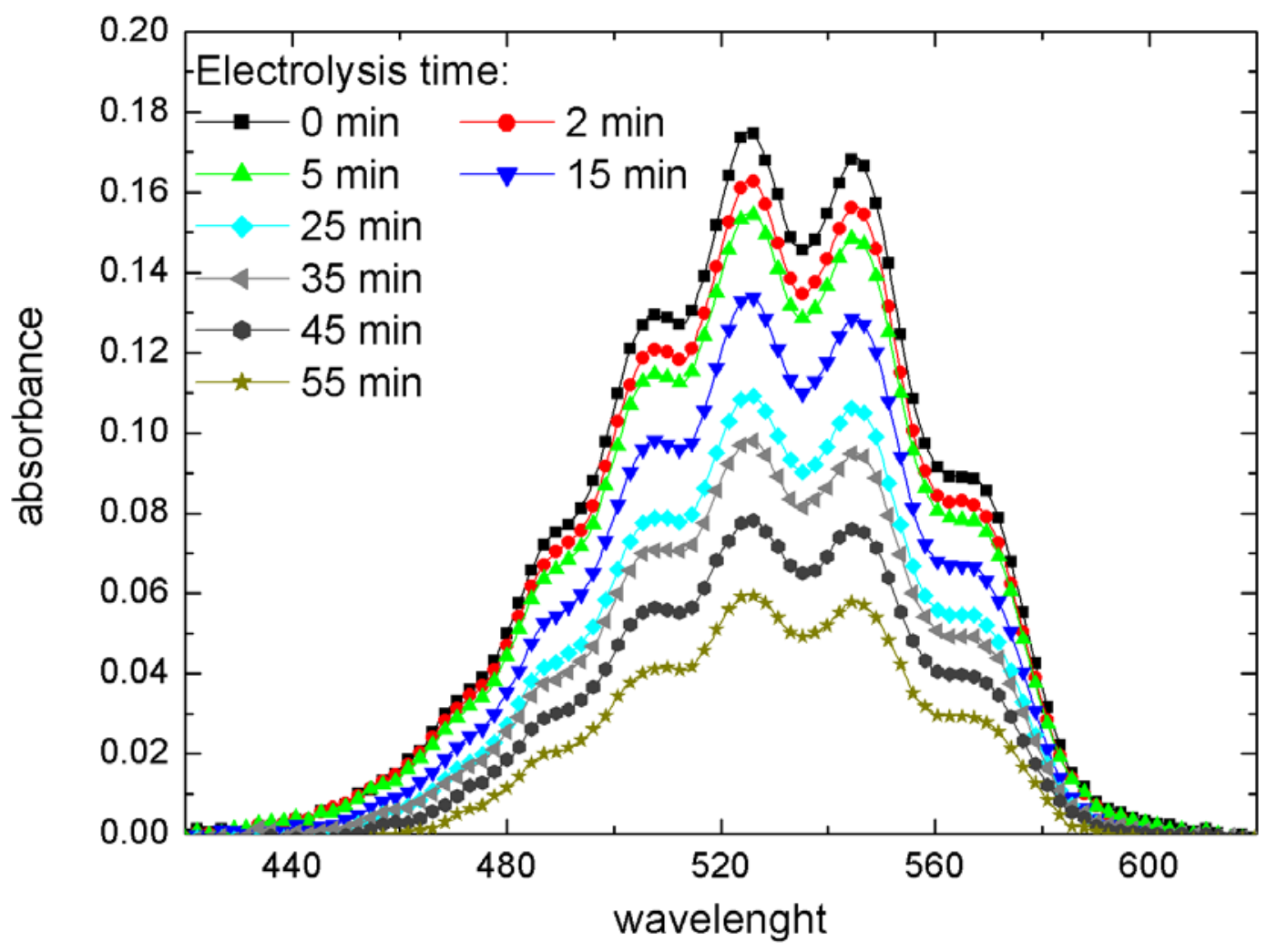

Fig. 8 Evolution of the absorbance spectra of $\mathrm{KMnO}_{4}$ aqueous solutions during continuous AIROF electrode scanning in $\mathrm{N}_{2}$-saturated $0.5 \mathrm{M} \mathrm{H}_{2} \mathrm{SO}_{4}$ from 1.5 to $2 \mathrm{~V}$ at $100 \mathrm{mV} / \mathrm{s}$ 


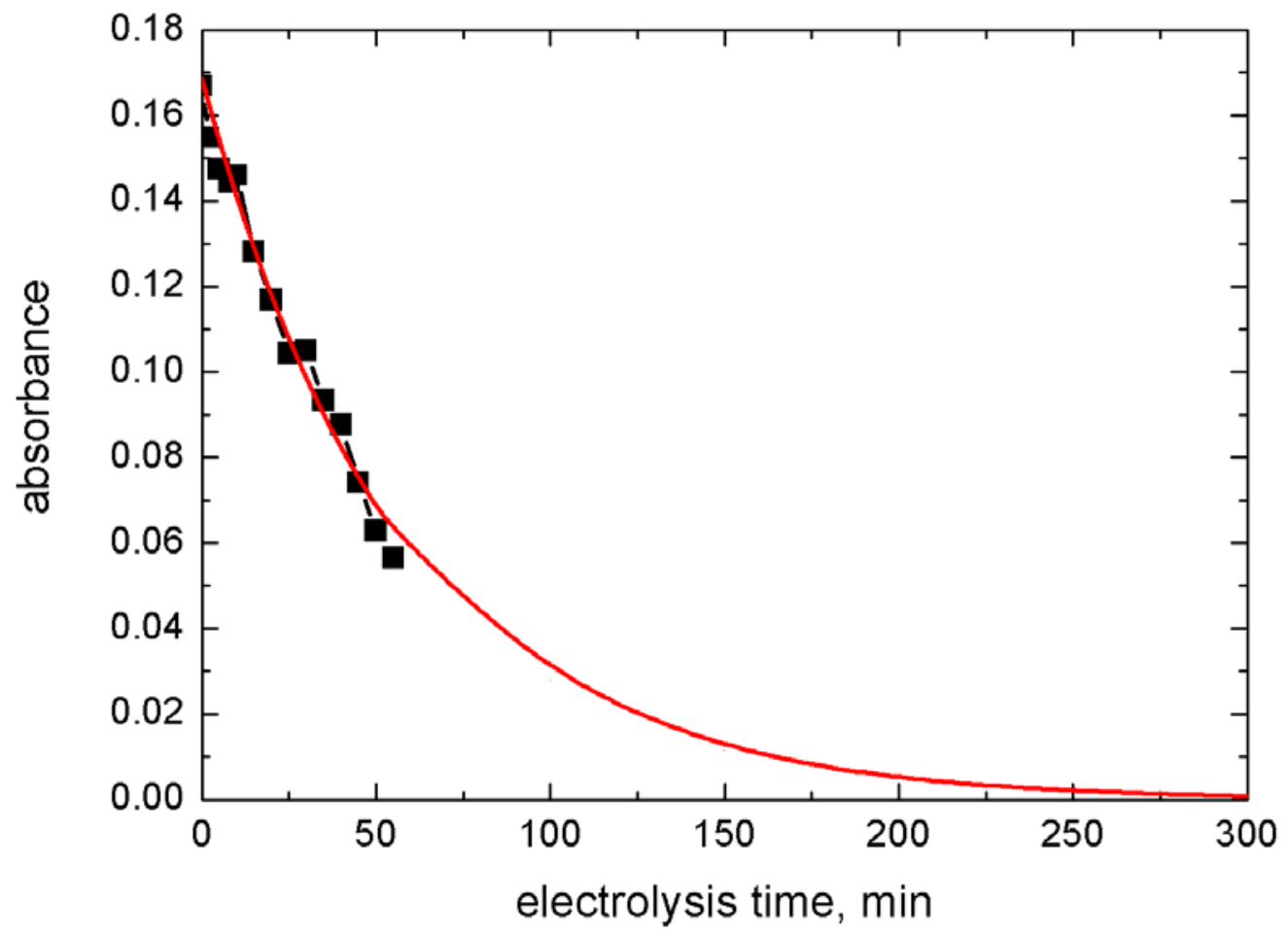

Fig. 9 Decreasing of the intensity of the $\mathrm{KMnO}_{4}$ absorption peak during oxygen evolution reaction on AIROF electrode 

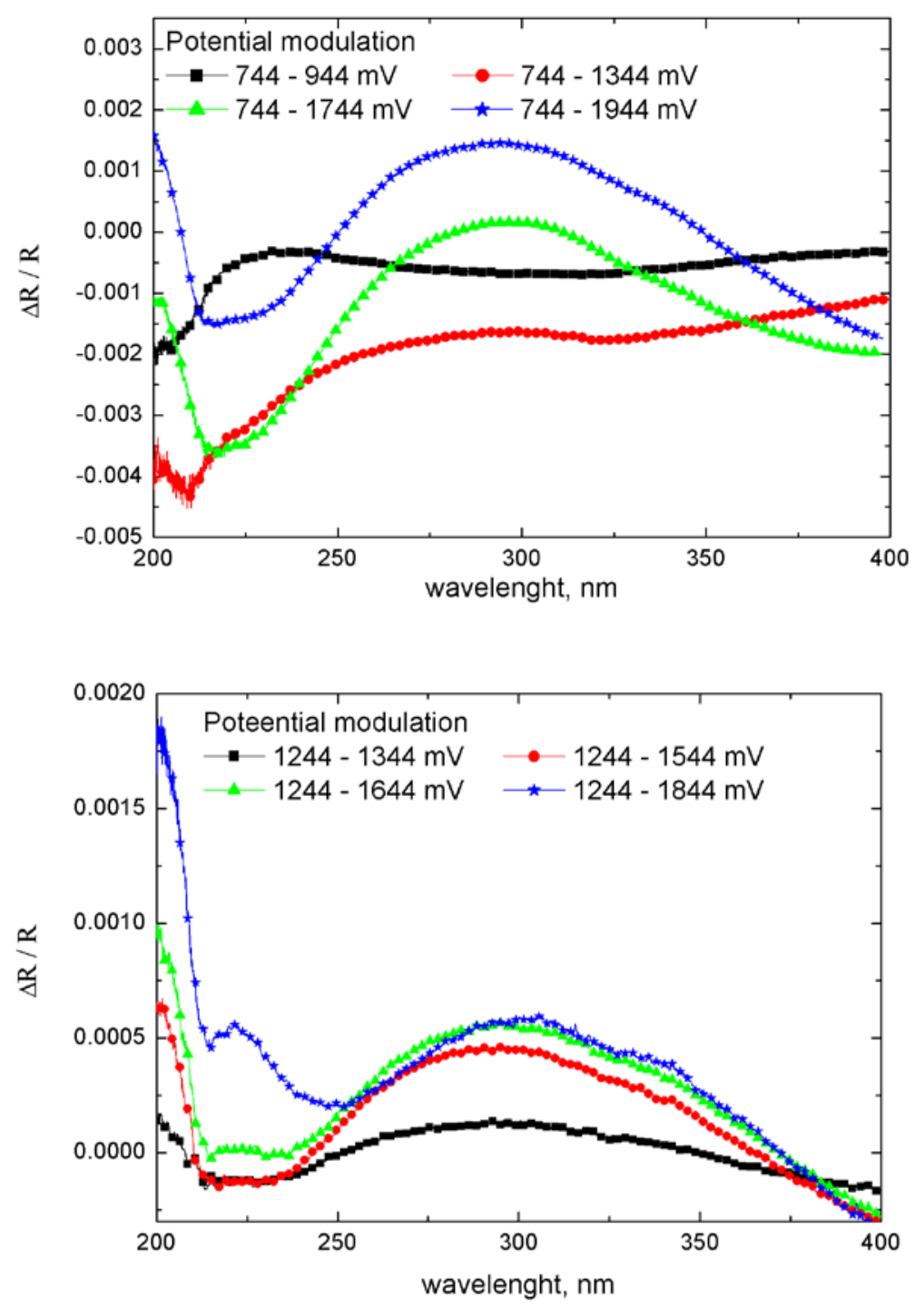

b

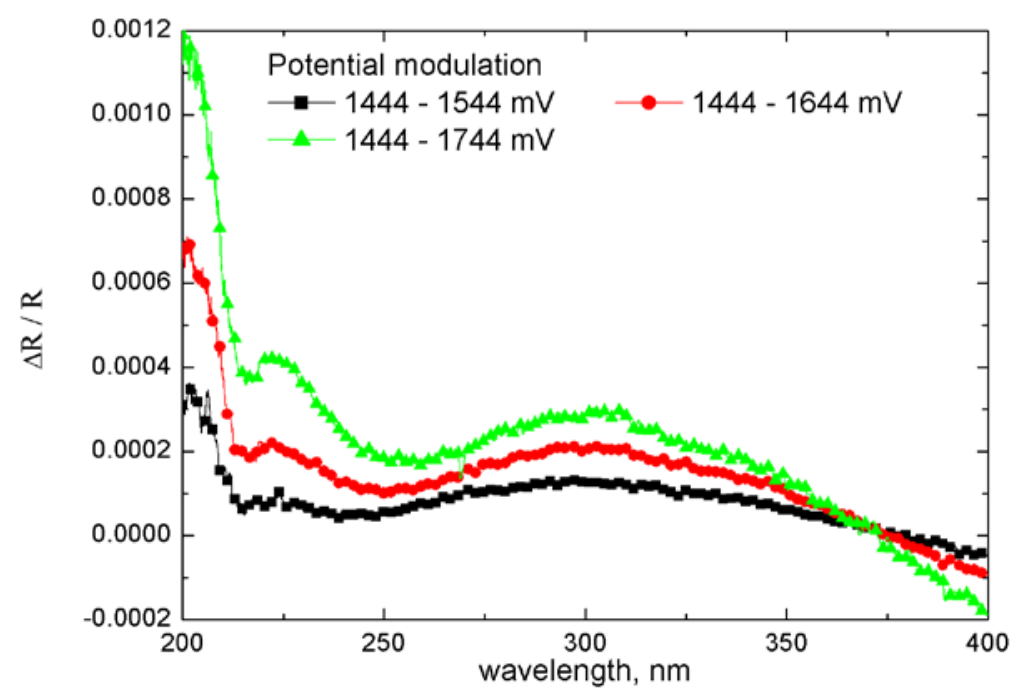

Fig. 10 PMR spectra of the AIROF electrode in $0.5 \mathrm{M}$ $\mathrm{HClO}_{4}$. The negative limit of the potential modulation was kept constant at a) $744 \mathrm{mV} \mathrm{b}$ ) $1244 \mathrm{mV}$ and c) $1444 \mathrm{mV}$. The modulation amplitude was increased by increasing the positive limit of the modulation as indicated in the figure. The modulation frequency was $63 \mathrm{~Hz}$ 


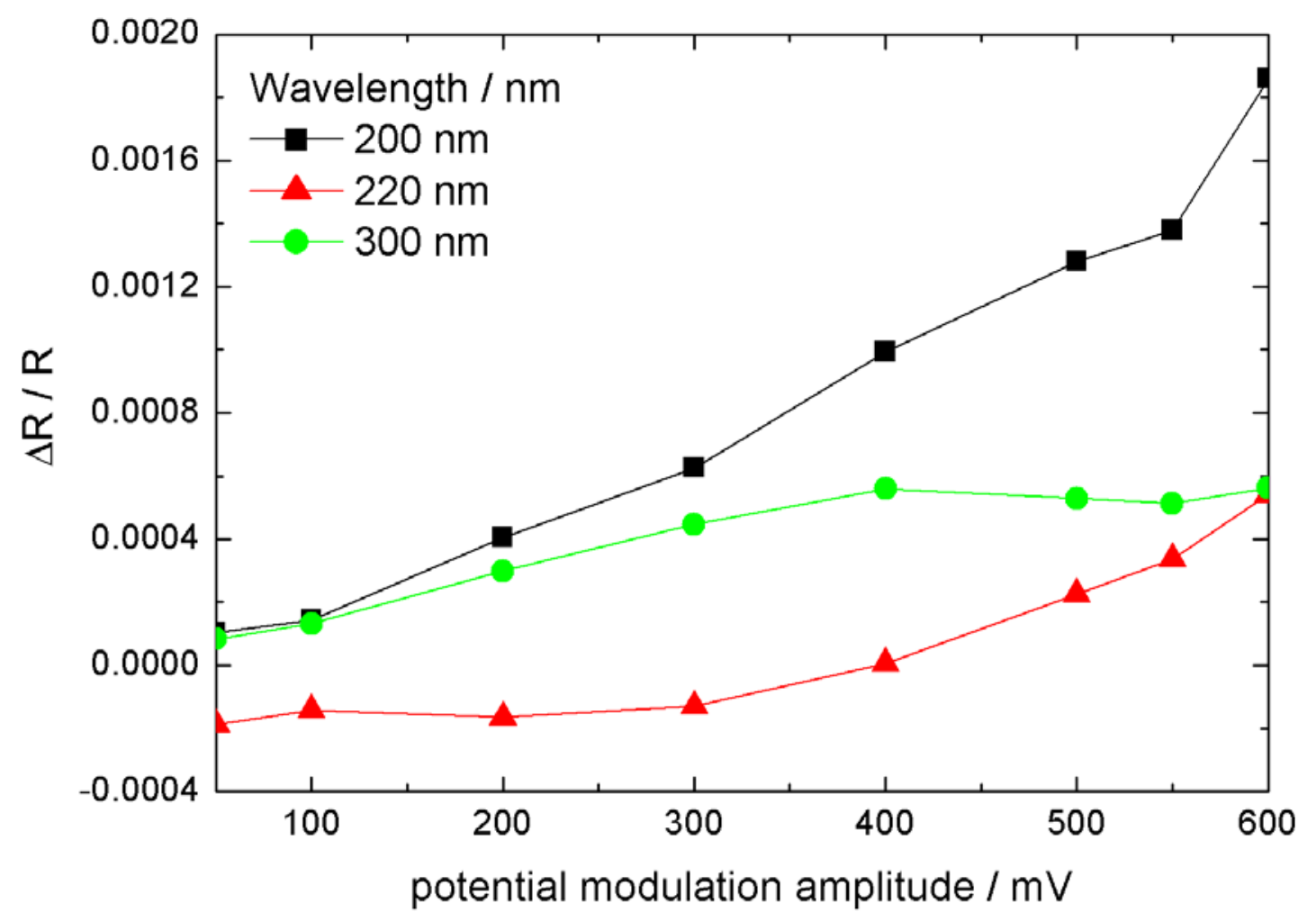

Fig. 11 Dependence of the intensity of the PMRS signal on the modulation amplitude at different wavelengths recorded in $0.5 \mathrm{M} \mathrm{HClO}_{4}$. Minimal modulation potential - $1244 \mathrm{mV}$, modulation frequency $-63 \mathrm{~Hz}$ 


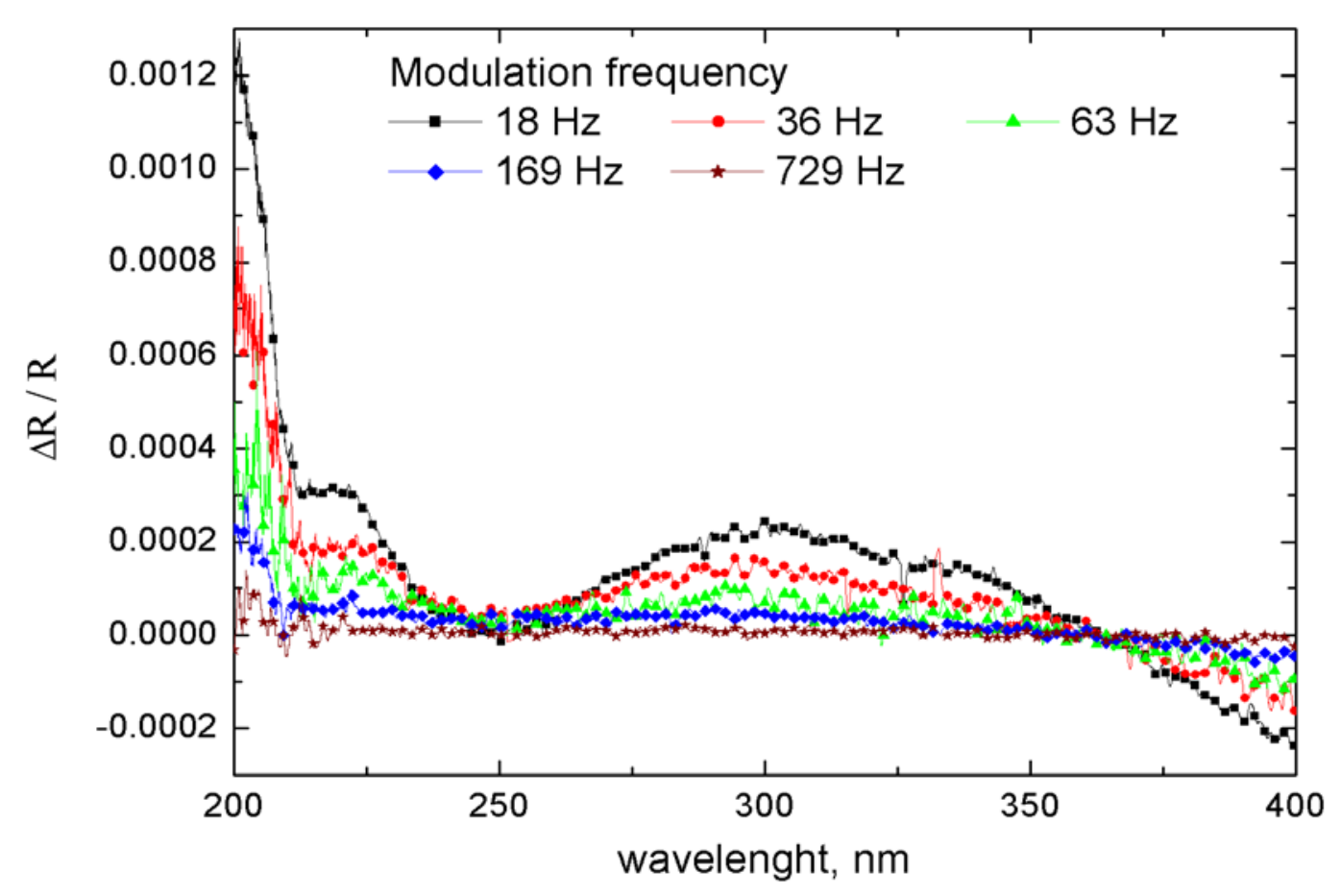

a

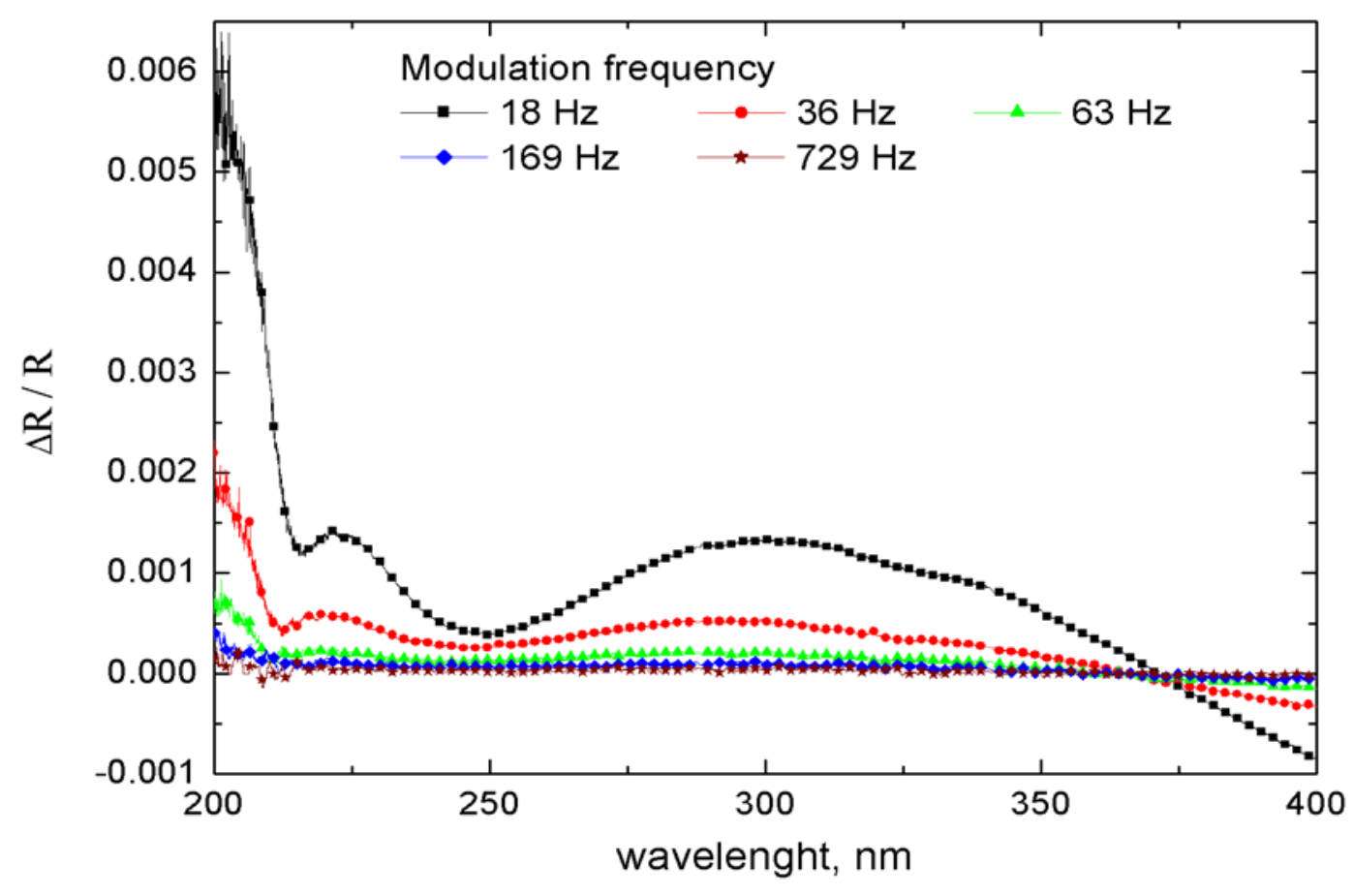

b

Fig. 12 PMR spectra of AIROF in $0.5 \mathrm{M} \mathrm{HClO}_{4}$ between the following potential modulation limits: a) $1469-1619 \mathrm{mV}$ b) $1344-1744 \mathrm{mV}$. Spectra were reordered at different frequencies, as indicated in the figure. 


\section{References}

[1] Abbott D. Proceed. of IEEE, 2010, 98, N 1, 42 - 66

[2] Water electrolysis and renewable energy systems, FuelCellToday, 2013

[3] Kroposki B., Levene J., Harrison K., Sen P.K., Novachek F. Tech. report, 2006, NREL/TP-58140605

[4] Trasatti S., Lodi G. In S. Trasatti, ed. Electrodes of Conductive Metallic Oxides, Part B, 1980, 1, 521, Elsevier, Amsterdam

[5] Kotz R., Stucki S. Electrochim. Acta, 1986, 31 (10), 1311 - 1316

[6] Trasatti S. Electrochim. Acta, 1991. 36(2), 225 - 241

[7] Man I. Doctoral thesis, theoretical study of electro-catalysts for oxygen evolution, 2011

[8] Owe L.E., Tsypkin M., Wallwork K.S., Haverkamp R.G., Sunde S. Electrochim. Acta, 2012, 70, $158-164$

[9] Bockris J. J. Chem. Phys., 1956, 24, 817 - 827

[10] Matsumoto Y., Sato E. Mater. Chem. Phys., 1986, 14, 397 - 426

[11] Trasatti S.,. In H. Wendt, ed. Electrochemical Hydrogen Technologies, 1990, 104, Elsevier Publishing, Amsterdam

[12] Lodi G., Sivieri E., De Battisti A., Trasatti S. J. Appl. Electrochem., 1978, 8, 135 - 143

[13] Valdez A., Qu Z.-W., Kroes G.-J., Rossmeisl J., Nørskov J.K. J. Phys. Chem. C, 2008, 112, 9872 - 9879

[14] Rossmeisl J., Logadottir A., Nørskov J.K. Chem. Phys. 2005, 319, 178 - 184

[15] Yang X., Baik M. J. Am. Chem. Soc., 2008, 130, 16231 - 16240

[16] Rossmeisl J., Qu Z.-W., Zhu H., Kroes G.-J., Nørskov J.K. J. Electroanal. Chem., 2007, 607, $83-89$

[17] Busch M., Ahlberg E., Panas I. Phys. Chem. Chem. Phys., 2011, 13, 15069 - 15076

[18] Busch M., Ahlberg E., Panas I. Phys. Chem. Chem. Phys., 2011, 13, 15062 - 15068

[19] Macounova K., Makarova M., Krtil P. Electrochem. Commun., 2009, 11, 1865 - 1868

[20] Petrykin V., Macounova K., Shlyakhtin O.A, Krtil P. Angew. Chem. Int. Ed., 2010, 49, 4813 - 4815

[21] Fierro S., Nagel T., Baltruschat H., Comninellis C. Electrochem. Commun., 2007, 9, 1969 - 1974

[22] Yeo B.S., Klaus S.L., Ross P.N., Mathies R.A., Bell A.T. ChemPhysChem, 2010, 11, 1854 - 1857

[23] Sivasankar N., Weare W., Frei H. J. Am. Chem. Soc., 2011, 133, 12976

[24] Sawyer D.T., Valentine J.S. Acc. Chem. Res., 1981, 14, 393- 12979

[25] Bard A.J., Parsons R., Jordan J. Standard potentials in aqueous solutions, 1985, M. Dekker

[26] Ando Y., Tanaka T. Int. J. Hydrogen Energy, 2004, 29, 1349 - 1354

[27] Yu T. H., Goddard W.A. J. Am. Chem. Soc., 2011, 133, 19857 - 19863

[28] Michaud P-A., Panizza M., Ouattara L., Diaco T., Foti G., Comninellis Ch. J. Appl. Electrochem., 2003, 33, 151 - 154

[29] Marshall A.T., Sunde S., Tsypkin M., Tunold R. Int. J. Hydrogen Energy, 2007, 32, 2320 - 2324

[30] Gottesfeld S., McIntryre J.D.E., Beni G., Shay J.L. Appl. Phys. Lett.,1978, 33, 208 - 210

[31] Jiang L., Colmenares L., Jusys Z., Behm R.J. J. Electrochem. Soc., 2008, 155, B908 - B914

[32] Katsounaros I., Schneider W.B., Meier J.C., Benedikt U., Biedermann P.U., Auer A.A.,

Mayrhofer K.J.J. Phys. Chem. Chem. Phys., 2012, 14, 7384 - 7391

[33] Katsounaros I., Schneider W.B., Meier J.C., Benedikt U., Biedermann P.U., Cuesta A., Auerb

A.A., Mayrhofer K.J.J., Phys.Chem. Chem. Phys., 2013, 15, 8058 - 8068

[34]Ayata S., Stefanova A., Ernst S., Baltruschat H., J. Electroanal. Chem, 2013, 701, 1 - 6

[35]Foller P.C., Tobias C.W., J. Electrochem. Soc., 1982, 129, 506 - 515

[36] Nemes A., Fábián I., van Eldik R., J. Phys. Chem. A, 2000, 104, 7995-8000

[37] Kinoshita K., Electrochemical Oxygen Technology, John Wiley \& Sons, New York, 1992, 16

[38]Knake R., Hauser P.C., Anal. Chem., 2002, 459, 199 - 207

[39]Kinoshita K., Electrochemical Oxygen Technology, John Wiley \& Sons, New York, 1992, 373

[40] Lervik I.A., Tsypkin M., Owe L.E., Sunde S. J. Electroanal. Chem., 2010, 645, 135 - 142

[41] Gottesfeld S., Srinivasan S. J. Electroanal. Chem., 1978, 86, 89 - 104

[42] McIntyre J.D.E., Basu S., Peck W.F., Brown W.L., Augustyniak W.M. Phys. Rev. B, 1982, 25,

$7242-7254$ 
[43] Kotz R., Neff H., Stucki S. J. Electrochem. Soc., 1984, 131, 72 - 76

[44] Paukert T.T., Johnson H.S. J. Chem. Phys., 1972, 56, 2824 - 2838 